\title{
GEOMAGIA50.v3: 1. general structure and modifications to the archeological and volcanic database
}

\author{
Maxwell C Brown ${ }^{1 *}$, Fabio Donadini ${ }^{2}$, Monika Korte ${ }^{1}$, Andreas Nilsson ${ }^{3,4}$, Kimmo Korhonen $^{5}$, \\ Alexandra Lodge ${ }^{3,6}$, Stacey N Lengyel ${ }^{7}$ and Catherine G Constable ${ }^{8}$
}

\begin{abstract}
Background: GEOMAGIA50.v3 is a comprehensive online database providing access to published paleomagnetic, rock magnetic, and chronological data from a variety of materials that record Earth's magnetic field over the past $50 \mathrm{ka}$.

Findings: Since its original release in 2006, the structure and function of the database have been updated and a significant number of data have been added. Notable modifications are the following: (1) the inclusion of additional intensity, directional and metadata from archeological and volcanic materials and an improved documentation of radiocarbon dates; (2) a new data model to accommodate paleomagnetic, rock magnetic, and chronological data from lake and marine sediments; (3) a refinement of the geographic constraints in the archeomagnetic/volcanic query allowing selection of particular locations; (4) more flexible methodological and statistical constraints in the archeomagnetic/volcanic query; (5) the calculation of predictions of the Holocene geomagnetic field from a series of time varying global field models; (6) searchable reference lists; and (7) an updated web interface. This paper describes general modifications to the database and specific aspects of the archeomagnetic and volcanic database. The reader is referred to a companion publication for a description of the sediment database.
\end{abstract}

Conclusions: The archeomagnetic and volcanic part of GEOMAGIA50.v3 currently contains 14,645 data (declination, inclination, and paleointensity) from 461 studies published between 1959 and 2014. We review the paleomagnetic methods used to obtain these data and discuss applications of the data within the database. The database continues to expand as legacy data are added and new studies published. The web-based interface can be found at http:// geomagia.gfz-potsdam.de.

Keywords: Geomagnetism; Paleomagnetism; Archeomagnetism; Database; GEOMAGIA50

\section{Findings \\ Introduction}

Databases are a vital component of the global infrastructure of science. In addition to ensuring the longevity of data, they enable the investigation of scientific ideas beyond those envisaged in the study for which the data were originally obtained. Furthermore, they encourage discourse on scientific standards, promote transparency in reporting on research, and ensure an ongoing return from publicly funded projects. Modern databases serve as

\footnotetext{
*Correspondence: mcbrown@gfz-potsdam.de

1 GFZ German Research Centre for Geosciences, Telegrafenberg, 14473

Potsdam, Germany

Full list of author information is available at the end of the article
}

digital libraries for research, with data archived at multiple levels and sophisticated search and analysis tools that allow users to find, visualize, and analyze a greater amount of data than ever before.

In paleomagnetic research there is a significant history of compiling published data stemming from the early paleomagnetic pole lists (e.g., Irving (1959)) and the first paleointensity lists (e.g., Smith (1967)), which provided minimal printed summaries of important results at the time. These continually updated lists acknowledged the significant effort in acquiring data, including the reality that it is not always possible to repeat field or experimental work, and allowed future generations to build new interpretations that took into account pre-existing

\section{Springer}

C 2015 Brown et al. This is an Open Access article distributed under the terms of the Creative Commons Attribution License (http://creativecommons.org/licenses/by/4.0), which permits unrestricted use, distribution, and reproduction in any medium, provided the original work is properly credited. 
results. The same advantages apply to more modern paleomagnetic and rock magnetic data compilations based on relational databases (beginning with the IAGA Global Paleomagnetic Database (GPMDB), Lock and McElhinny 1991; McElhinny and Lock 1996; Pisarevsky 2005) that have now evolved the potential to store highly detailed information ranging from raw field and laboratory measurements through multiple processing steps to results (e.g., MagIC, Constable et al. (2006); Jarboe et al. (2012)).

The aim of the GEOMAGIA50 database is to provide easy access to the significant amount of paleomagnetic, rock magnetic, and chronological data covering the past 50 ka that have been obtained from archeological materials, volcanic rocks, and sediments. These data have a range of applications within geosciences. Determining the temporal and spatial evolution of the geomagnetic field improves our understanding of the geodynamo and deep Earth processes; geomagnetic shielding against solar wind and galactic cosmic rays; the modulation of cosmogenic radionuclide production; and interactions between the geomagnetic field and climate. Robustly constrained temporal variations in the geomagnetic field can be used to date the time of firing of archeological materials, the emplacement of lavas, or the deposition of sediments. Furthermore, variations in the rock magnetic properties of sediments can reflect changes in environment, climate, and anthropogenic impact. Greater detail on the applications of data within GEOMAGIA50 are described in the 'Applications of archeomagnetic and vol canic data from GEOMAGIA50' section and a companion paper (Brown et al. 2015), which describes the substantial modifications made to the database to include sediment data.

GEOMAGIA50 originally began in 2006 as a database of global field intensity data from archeological and volcanic materials (Donadini et al. 2006; Korhonen et al. 2008). It built upon previous efforts to catalogue archeomagnetic and recent paleomagnetic results, on paper (e.g., Eighmy and Sternberg 1990; Smith 1967), as regional or global compilations (see the 'Archeological and volcanic data sources' section), or in digital databases (Liritzis and Lagios 1993; Perrin and Schnepp 2004; Sternberg et al. 1997; Tarling and Dobson 1995).

GEOMAGIA50 employs the philosophies of a Relational Database Management System (Codd 1970) and uses Standard Query Language (SQL), the official international language for database management systems, as recognized by the International Organization for Standardization (ISO). These principles underlie the IAGA paleomagnetic databases (e.g., Lock and McElhinny (1991)) and have been applied successfully in more recent paleomagnetic databases, MagIC (Constable et al. 2006) and PALEOMAGIA (Veikkolainen et al. 2014). Since 2008, GEOMAGIA50 has been queried 10,264 times (approximately 1,700 queries per year) and Donadini et al. (2006) and Korhonen et al. (2008) have 53 unique citations between them.

This paper and its companion (Brown et al. 2015) address updates and extensions to the most recent version of the GEOMAGIA50 database and web portal (GEOMAGIA50.v3). The first version of the database provided convenient access not only to intensity data spanning ages of 0 to $50 \mathrm{ka}$, but also included a wealth of information about any associated paleomagnetic directions, experimental and dating methods, materials, number of samples measured, and other metadata (see Korhonen et al. (2008)). A recognition of issues concerning the fidelity of archeological materials and lavas to accurately record the intensity of the geomagnetic field led to the inclusion of detailed metadata on paleointensity methods. Constable and Korte (2015) and Donadini et al. (2010) give recent overviews of data types and experimental methods employed to gain magnetic field information from archeological material, lavas and sediments, in particular for the Holocene epoch.

Since the release of the first version of GEOMAGIA50, a continued interest in improving global spherical harmonic models of the Holocene geomagnetic field, initiated by the work of Constable et al. (2000) and Korte and Constable (2003), triggered a desire to include more comprehensive directional data from archeological and volcanic materials in an updated version of the database (GEOMAGIA50.v2). Concurrently, the production of new archeomagnetic data strongly increased as a result of the European AARCH project (2002 to 2006) (Figure 1), which aimed to improve European regional reference curves for geomagnetic dating of archeological materials (e.g., Gómez-Paccard et al. (2006a); Márton and Ferencz (2006); Schnepp and Lanos (2006); Tema et al. (2006); Zananiri et al. (2007)). In June 2008, archeo/volcanic directions and intensity data with increased metadata were made accessible through an updated data model in GEOMAGIA50.v2 (http://geomagia.ucsd.edu.), which included global data sets compiled for specific modeling purposes (Constable et al. 2000; Korte et al. 2005; Genevey et al. 2008; Donadini et al. 2009) and incorporated data from the AARCH project. At this time, it was also envisaged that future modifications would allow incorporation of sediment records; however, this was not realized until GEOMAGIA50.v3 (see Brown et al. 2015).

In addition, the importance of equatorial and southern hemisphere data has been recognized for global modeling (e.g., Korte and Constable (2005)) and for understanding the evolution of the South Atlantic anomaly (e.g., Mandea et al. (2007)). This has driven recent efforts to obtain archeomagnetic data from Argentina (Goguitchaichvili et al. 2010, 2011), Brazil (Hartmann et al. 2010, 2011), India (Venkatachalapathy et al. 2013), 


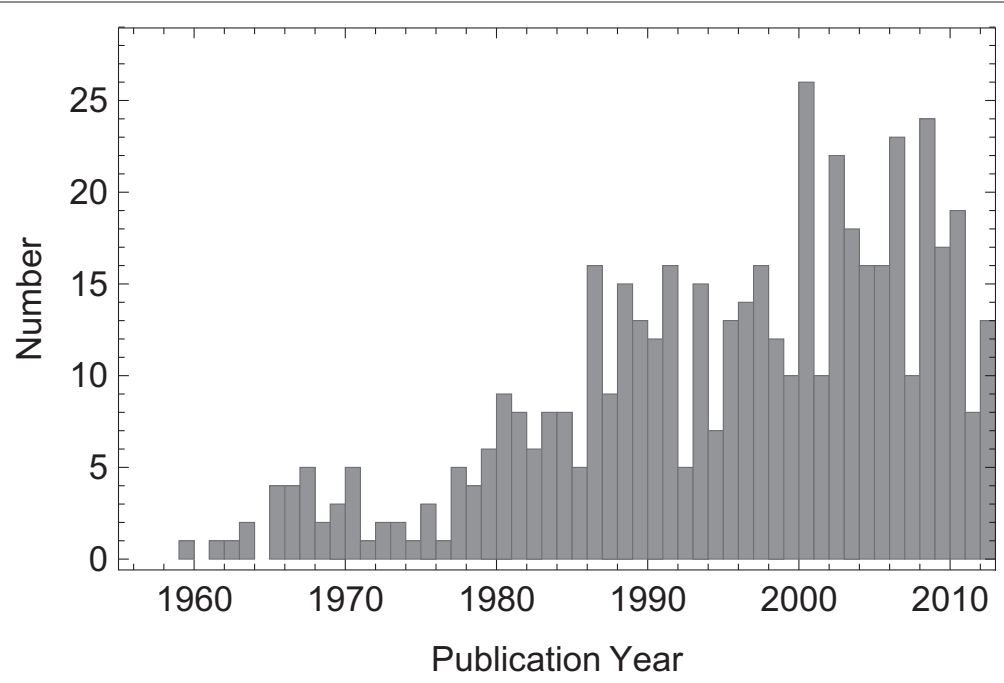

Figure 1 Number of archeomagnetic and volcanic studies published per year included in GEOMAGIA50.v3.

Senegal and Mali (Mitra et al. 2013), South Africa (Neukirch et al. 2012), and the SW Pacific (Stark et al. 2010). Furthermore, determining the age of magnetization is a major challenge; however, the quality of the age determination is crucial, e.g., when interpreting temporal variations in regionally compiled archeomagnetic curves (e.g., De Marco et al. (2008); Hagstrum and Blinman (2010); Márton (2010); Shaar et al. (2011); Tema and Kondopoulou (2011)) or in comparing magnetic field variations in sediment records from different locations (e.g., Nilsson et al. $(2010,2014)$ ). This has led to the expansion of the chronological metadata included in the latest version of the database.

In parallel with the development of GEOMAGIA50, databases under the Magnetics Information Consortium (MagIC; Constable et al. (2006)) have undergone systematic evolution from a somewhat different perspective. MagIC (started in 2003) intends to capture as much data and associated metadata as possible throughout the work flow from field and/or lab work to analysis and eventual publication. In contrast, the simpler structure and web query interface provided by GEOMAGIA50 provides a straightforward way to recover selected but extremely useful results with specific attributes from identified locations and age ranges. MagIC also accepts these more limited data sets, and since 2007, the collaborative intent has been to share information between GEOMAGIA50 and MagIC, so that effort expended in populating one database does not need to be duplicated later.

This paper begins by describing what we see as the major successes and future applications of the database ('Applications of archeomagnetic and volcanic data from GEOMAGIA50' section). This is followed by the principles behind the database ('Principles of the GEOMAGIA50.v3 database' section), the general structure and function of the updated database ('General structure of the MySQL database' section), documentation of the data types stored within GEOMAGIA50.v3 ('Archeological and volcanic data types' section), and the sources of the data ('Archeological and volcanic data sources' section). A summary of the key changes between GEOMAGIA50.v1 and GEOMAGIA50.v3 is given in the "Modifications and updates to the archeomagnetic and volcanic database' section. Although version 2 data were described in part in Donadini et al. (2009), no comprehensive publication described the data model and the web-based user query form of GEOMAGIA50.v2. We remedy this by documenting the update of the database to GEOMAGI50 .v3, which has been expanded to accommodate sedimentary paleomagnetic, rock magnetic, and geochronological data (see Brown et al. (2015)), in addition to a wider range of results from archeological and volcanic materials ('Modifications and updates to the archeomagnetic and volcanic database' section). We note in particular the inclusion of a greater number of archeomagnetic and volcanic directional data, more extensive chronological data and additional metadata, as well as modifications to the user interface that allow more refined data searches, the calculation and plotting of geomagnetic field model predictions, and visualization of data locations within Google Earth.

The 'User interface: GEOMAGIA50.v3 web page' section describes the rationale behind the web-based archeomagnetic/volcanic query form. Finally, Additional file 1 contains a user guide to the archeomagnetic/volcanic 
query form and a description of the global Holocene geomagnetic field models that can be queried through the database interface.

The database is maintained in mirror versions on servers at the German Research Centre for Geosciences GFZ in Potsdam, Germany (http://geomagia.gfzpotsdam.de), and at the University of California at San Diego, USA (http://geomagia.ucsd.edu/).

\section{Applications of archeomagnetic and volcanic data from GEOMAGIA50}

Data from GEOMAGIA50 have been used in studies of geomagnetism, the deep Earth, the space environment, climate, volcanism, and archeology. A particularly notable use has been in the creation of temporally continuous models of the global Holocene geomagnetic field (e.g., Korte et al. (2009, 2011); Licht et al. (2013); Nilsson et al. (2014); Panovska et al. (2015); Pavón-Carrasco et al. (2014a)) and regional models of the geomagnetic field (Pavón-Carrasco et al. 2010; Pavón-Carrasco et al. 2014b), for which data from GEOMAGIA50 are a vital component. These models allow mapping of changes in the geomagnetic field at Earth's surface and core-mantle boundary through time, placing constraints on the evolution of the past geomagnetic field.

As global field models are constructed to recreate the field at the core-mantle boundary, they have the potential to be used to understand the geodynamo and have been used to investigate core flow (Dumberry and Finlay 2007; Wardinski and Korte 2008; Livermore et al. 2014), with possible implications for length of day variations on millennial time scales (Dumberry and Bloxham 2006); the behavior of high latitude flux patches (Korte and Holme 2010; Amit et al. 2011); hemispheric field asymmetries related to archeomagnetic jerks (Gallet et al. 2009); discrete scale invariance across geodynamo time scales (Jonkers 2007); and similarities with the characteristics of dynamo simulations (Christensen et al. 2011; Heimpel and Evans 2013; Davies and Constable 2014). Calculations of dipole eccentricity using CALS3k.4b (Korte and Constable 2011) and CALS10k.1b (Korte et al. 2011), coupled with observations of hemispherical variations in seismic velocity at the top of the Earth's inner core, motivated Olson and Deguen (2012) to investigate persistent eccentricity in numerical dynamo simulations and they suggested lopsided solidification within the inner core. Brown et al. (2007), Valet and Plenier (2008), Valet et al. (2008), and Valet et al. (2012) investigated surface field morphologies and statistical characteristics of the field during simulated reversals and excursions by using CALS7K.2 (Korte and Constable 2005) and CALS10k.1b (Korte et al. 2011) and imposing changes on the axial dipole component of the field while leaving the non-dipole field unchanged.
Studies of cosmogenic radionuclide production (e.g., ${ }^{14} \mathrm{C},{ }^{10} \mathrm{Be},{ }^{36} \mathrm{Cl}$, and ${ }^{3} \mathrm{He}$ ) in Earth's atmosphere have employed estimates of dipole strength from the CALSxk series of models to calibrate variations in production activity (e.g., Kovaltsov et al. (2012); Lifton et al. (2014); Schimmelpfennig et al. (2011)). Production rates have then been used to calculate past solar activity (Delaygue and Bard 2011; Snowball and Muscheler 2007; Usoskin et al. 2006) and surface exposure ages (Lifton et al. 2008; Balco et al. 2008). Similarly, studies of cosmic ray ionization in the troposphere (Usoskin et al. 2008, 2010) and theoretical models of the inner proton radiation belt (Selesnick et al. 2007) have incorporated geomagnetic constraints from CALS7K.2. Geomagnetic field models have also been used to estimate the occurrences of aurora at mid-latitudes in the Northern Hemisphere over the past $10 \mathrm{ka}$ (Korte and Stolze 2014).

When age control is uncertain in sediment and archeological studies, the time varying location dependent outputs of models have been compared with the paleomagnetic field recorded in these materials. This has aided in understanding the timing of climate events recorded in sediments (e.g., Antoniades et al. (2011); Barletta et al. (2010); Ledu et al. (2010)) and the dating of archeological and volcanic materials (see Lodge and Holme (2009), Pavón-Carrasco et al. (2009), and Villasante-Marcos and Pavón-Carrasco (2014)). Models based on archeological data have been used to study the lock-in process in precisely dated sediment sequences (Mellström et al. 2015).

In addition to global geomagnetic field modeling, archeological and volcanic data within GEOMAGIA50 can be used to investigate statistical characteristics of the geomagnetic field (Donadini et al. 2007; Roberts et al. 2013); develop archeomagnetic reference curves (e.g., Fanjat et al. (2013); Hellio et al. (2014); Márton (2010); Tema and Kondopoulou (2011)), which aid in the dating of archeological materials that form the backbone of archeological studies; understand material and methodological bias in paleointensity estimates (Donadini et al. 2007); calculate mean dipole moments (Knudsen et al. 2008); and explore links between climate and the geomagnetic field (Knudsen and Riisager 2009).

Further applications of archeological and volcanic data from GEOMAGIA50 include dating of eruptive episodes through comparison of paleomagnetic directions and intensities recorded in lavas and volcanic deposits with reference curves (e.g., Di Chiara et al. (2014); Holcomb et al. (1986); Speranza et al. (2008)) (however, caution must be taken when relocating reference curves to eruption locations when the distance between the two is large). Absolute paleointensity data can be used to calibrate relative paleointensity (RPI) records from sediments (Donadini et al. 2009; Korte and Constable 2006) which can refine global models of the geomagnetic field and 
improve global stacks of RPI (e.g., SINT2000 (Valet et al. 2005) and PISO-1500 (Channell et al. 2009)). Finally, paleomagnetic data within GEOMAGIA50 have the potential to be incorporated in data assimilation strategies for modeling and forecasting the geomagnetic field (see Fournier et al. (2010); Kuang et al. $(2008,2009))$.

\section{Principles of the GEOMAGIA50.v3 database}

The GEOMAGIA50 database is based upon the principles of a Relational Database Management System (Codd 1970). Users access the data through a web-based interface. There are three primary components to the database design model (Figure 2):
1. The digital storage and management of the data;

2. The web-based interface (query forms and HTML output);

3. Programming that transfers information back and forth between (1) and (2).

We employ the LAMP (Linux, Apache, MySQL, PHP) model of web service management to produce a dynamic web-based database for the user. All components of this model are open source.

Data are primarily stored and managed using the ORACLE MySQL database management system on a Linuxbased server at the Helmholtz Centre, GFZ Potsdam.

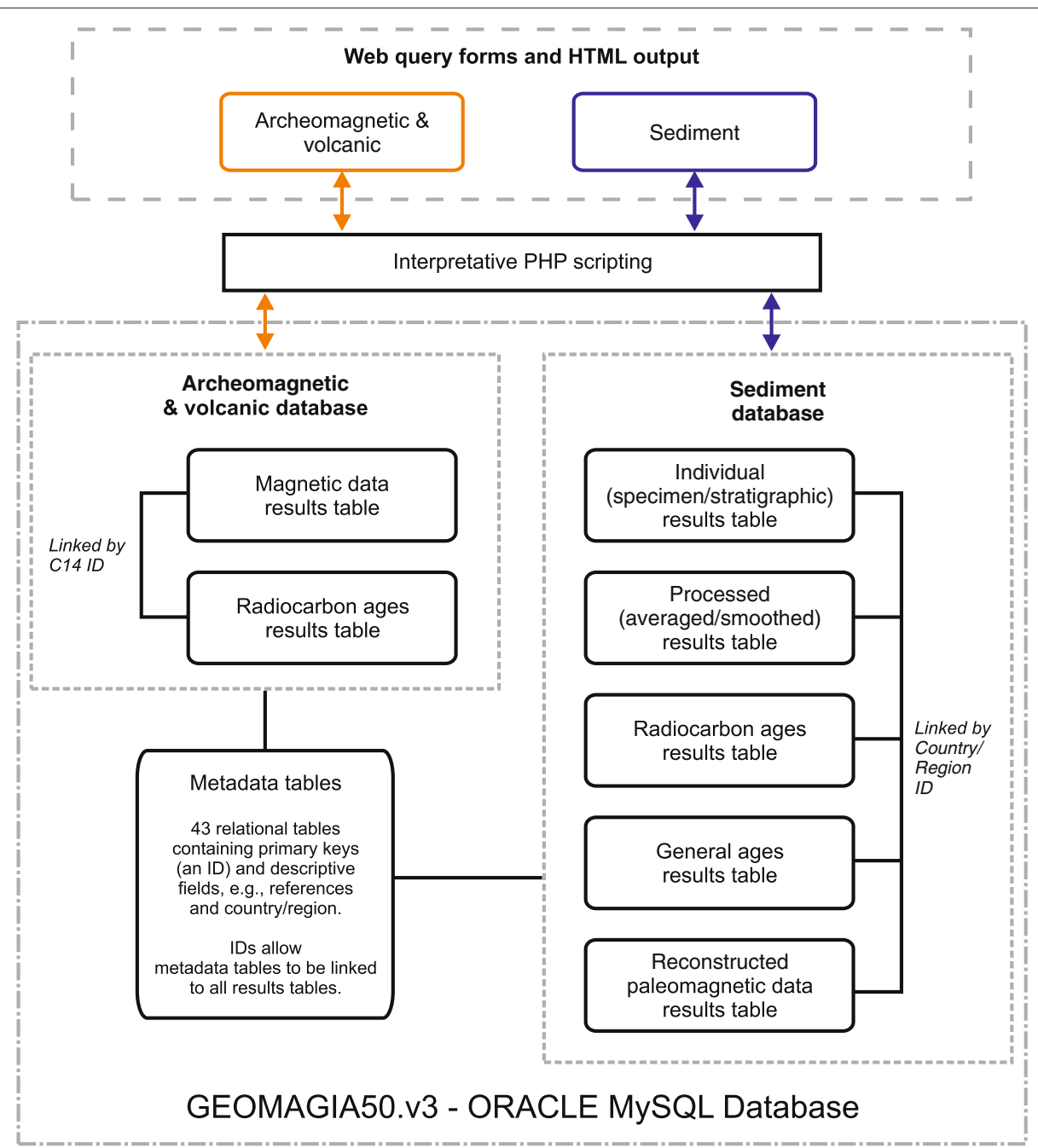

Figure 2 A schematic of the general structure of the GEOMAGIA50.v3 database. The grey dot-dashed box contains relational tables (results and metadata tables) housed within the ORACLE MySQL database. The grey short-dashed lines nominally divide the results tables between those which contain archeomagnetic and volcanic data and those containing sedimentary data. The long-dashed box contains the three parts of the web page visible to the user. Lines with arrow heads represent the two-way transfer of information between different parts of the database (e.g., query commands and data return). Orange represents archeomagnetic and volcanic commands and data transfer; blue $=$ sediments. Solid black lines show the links between results tables annotated by the linking ID. The elements of the figure are explained further in the 'Principles of the GEOMAGIA50.v3 database' section. 
The database is mirrored at the University of California, San Diego. The long-term availability of the database is secured through the commitment of both institutions. The relational nature of the MySQL database allows a collection of tables to be manipulated and joined using the SQL language. This avoids repetition of fields within different tables as the information only needs to be entered once. In addition, it allows complex queries to be composed and data sets based upon multiple search criteria to be returned.

We chose to employ a web-based user interface, rather than an installation-based software such as for the IAGA databases (http://www.ngdc.noaa.gov/geomag/ paleo.shtml), as it has the following advantages:

1. No proprietary software are required by the user;

2. It requires only access to the internet and a web browser;

3. It is platform independent (there are only minor differences whether run on Windows, Macintosh or Linux operating systems);

4. The data and metadata available to the user can be dynamically updated as new data become available, rather than a new software package being required;

5. It has global visibility as it is returned in web search engines.

Requests are processed using an Apache HTTP web server. This allows us to implement server-side programming languages that handle requests from the web page and return data and plots from the server to the web page. We use the PHP (Hypertext Preprocessor) scripting language to transform users' data requests into query statements that can be read by the MySQL database. Java script is used to provide additional web page functionality. PHP is used to process the data recalled by the database into a series of HTML tables and .CSV files that can be viewed online and downloaded from the web page (see 'Query results' section).

Graphical output ('Figures and downloads' section) is generated by first processing the data recalled from the database in a PHP script. Plots are then created using the Python programming language, stored on the server, and recalled to the web page through further PHP scripting.

Site-dependent output of a series of Holocene geomagnetic field models (see Additional file 1) can be generated as a .TXT file ('Query results' section) and plotted alongside the data ('Figures and downloads' section). The models are run using a series of Fortran routines. Again, the output is interpreted by the PHP coding and graphs are generated using Python.

The web pages are hosted at http://geomagia.gfzpotsdam.de/ and mirrored at http://geomagia.ucsd.edu/. The functionality of the web-based query form for the archeomagnetic and volcanic database (http://geomagia. gfz-potsdam.de/geomagiav3/AAquery.php) is briefly described in 'Querying the database: the 'archeomagnetic and volcanic data' query form' section and in more detail in a user's guide in Additional file 1. The sediment query form is described in Brown et al. (2015). In addition to the web-based query forms, web-pages have been designed to recall metadata from the database. These include searchable lists of archeo/volcanic and sediment studies ('Web site features' section) and a glossary of identification numbers used to describe the metadata ('General structure of the MySQL database' section).

\section{General structure of the MySQL database}

GEOMAGIA50.v3 builds upon the database structure outlined in Korhonen et al. (2008) (herein referred to as K08). In this section we describe developments to the overall structure of the database and its main components. To aid this description, we have tabulated commonly referenced terms (Table 1). A schematic diagram outlines the general structure of the database (Figure 2).

A key development between versions 2 and 3 of the database is the inclusion of sediment data and this has expanded the database structure significantly. Sediment data are collected, measured, processed, and analyzed in different ways to archeological and volcanic data. We have therefore developed a series of structurally distinct results and metadata tables to accommodate the different and varied parameters measured in sediment studies. The structure of the sediment database and the content of the results tables are discussed thoroughly in Brown et al. (2015).

The version 3 database consists of two sets of results tables, those for the archeomagnetic and volcanic side of the database and those for the sediment side of the database (Figure 2). There are two archeomagnetic and volcanic results tables: a magnetic data results table and a radiocarbon age results table.

The magnetic data results table contains age ('Chronological data' section), paleomagnetic results ('Paleomagnetic data' section), and a variety of metadata ('Metadata' section). The full list of fields is shown in Additional file 1: Table S1. All entries have an associated age and represent data at the site level (as defined in Table 1). This is the most convenient option for presenting and analyzing time series of data. GEOMAGIA50 does not store sample or specimen paleomagnetic results (unless these are the only results available from a site) or rock magnetic data. It does not store the individual demagnetization or remagnetization steps used to determine a directional or intensity estimate of the geomagnetic field (see the 'Paleomagnetic data' section). In many cases, these data are not available, unless obtained directly from the author of a study. Although the provision of rock magnetic data is important 
Table 1 Glossary of terms employed in GEOMAGIA50

\begin{tabular}{|c|c|}
\hline Term & Description \\
\hline Entry & $\begin{array}{l}\text { A row of information within a results or } \\
\text { metadata table. } \\
\text { In database terminology this is often called } \\
\text { a record; however, within sediment stud- } \\
\text { ies, the use of record denotes a complete } \\
\text { data set. } \\
\text { An entry shows data at the site level. }\end{array}$ \\
\hline Field & $\begin{array}{l}\text { A column of information within a result or } \\
\text { metadata table. }\end{array}$ \\
\hline Identification number (ID) & $\begin{array}{l}\text { A number within a results table that links } \\
\text { to an identical number (the primary key) } \\
\text { within a metadata table, allowing the } \\
\text { return of a description of the ID. }\end{array}$ \\
\hline Location & $\begin{array}{l}\text { A geographical area with similar character- } \\
\text { istics, smaller than a country/region, which } \\
\text { can contain a number of sites, e.g., an } \\
\text { archeological excavation or a volcano. }\end{array}$ \\
\hline Metadata table & $\begin{array}{l}\text { A two dimensional relational table } \\
\text { containing a primary key field and } \\
\text { descriptive fields. }\end{array}$ \\
\hline Primary key & $\begin{array}{l}\text { A number that links an entry or parts of an } \\
\text { entry between relational tables. }\end{array}$ \\
\hline \multirow[t]{2}{*}{ Relational table } & $\begin{array}{l}\text { A table that can be related to another } \\
\text { by associations between tables and which } \\
\text { can be joined using the SQL language. } \\
\text { They negate repetition of fields between } \\
\text { tables by employing primary keys, which } \\
\text { allow values within one field to link to com- } \\
\text { plete entries or parts of entries between } \\
\text { tables. }\end{array}$ \\
\hline & $\begin{array}{l}\text { Results and metadata tables are relational } \\
\text { tables. }\end{array}$ \\
\hline Results table & $\begin{array}{l}\text { A large two dimensional relational table } \\
\text { with multiple fields and unlimited entries } \\
\text { containing results and IDs. }\end{array}$ \\
\hline Sample & $\begin{array}{l}\text { A portion of material obtained from a site, } \\
\text { which can be subdivided into specimens, } \\
\text { e.g., a fragment of a pot from which smaller } \\
\text { parts were taken or a drill core from a lava. }\end{array}$ \\
\hline Specimen & $\begin{array}{l}\text { The smallest division of a material used to } \\
\text { determine a measurement, e.g., a piece of } \\
\text { a pot fragment or a standard cylinder from } \\
\text { a lava drill core. }\end{array}$ \\
\hline Site & $\begin{array}{l}\text { A material/medium/stratum/geological unit } \\
\text { which can be assigned a unique age, e.g., a } \\
\text { pot, a layer at an archeological excavation } \\
\text { or a lava flow. }\end{array}$ \\
\hline
\end{tabular}

to understanding the reliability of palaeomagnetic data, rock magnetic data are generally reported at the specimen level and are therefore not easily accommodated in the current structure of the GEOMAGIA50 database. The MagIC database (Constable et al. 2006) has already developed the necessary structures to accommodate specimen level paleomagnetic and rock magnetic data and is the most suitable place to store these data.
The radiocarbon age results table is a new addition in version 3 of the database. It has been designed to accommodate experimental radiocarbon ages and their uncertainties at one standard deviation (see 'Chronological data' section). In addition, it shows the preferred ages and uncertainties of the author, the sample names used in a publication as well as the sample codes used by the radiocarbon dating facility ('Chronological metadata' section). The full list of fields are shown in Additional file 1: Table S2. The radiocarbon results table is associated with the magnetic data results table via an identification number (ID) called 'C14 ID'. This appears in the penultimate column of the magnetic data results table and is again found in the first column of the radiocarbon ages results table.

The sediment database contains five results tables (Figure 2). The content of the results tables and the rationale behind them is described in Brown et al. (2015). Every results table contains a country/region ID. This ID allows the tables to be joined within an MySQL statement when querying the database. This maximizes the efficiency of the relational table structure and only one statement is required to return entries from all the results tables related to a specific query.

In addition to the archeo/volcanic and sediment results tables, 43 metadata tables contain specific information about, e.g., paleomagnetic experimental details, specimens types, and references (see http://geomagia.gfzpotsdam.de/ID_glossary.php for a list of tables). Metadata for the archeo/volcanic database are discussed in detail in the 'Metadata' section. Sediment metadata are discussed in Brown et al. (2015). The use of metadata tables allows IDs to replace specific fields of metadata information within a results table. For example, each reference is assigned an ID. The metadata table will contain this ID (which acts as the primary key) followed by other fields for authors, year, journal, etc, (see Table ten, K08, for an example). Rather than the full reference being listed in a results table, only the reference ID is shown. When search criteria are specified by the user, a MySQL statement is constructed which joins the information within the results table and the metadata table and returns only references related to the specific query. Metadata tables can be used by both the archeo/volcanic and the sediment database, e.g., the country/region metadata table (http://geomagia. gfz-potsdam.de/ID_glossary.php\#CRID) and by multiple fields within a results table. This reduces the number of metadata tables required. This is the case for many fields in the sediment database. For example, there are multiple dating fields related to different types of dating methods. For each dating method an age can be reported, but as the statistical methods used to calculate the ages are applicable to all dating methods, they can be grouped within one 
metadata table. This one metadata table can then be called for all the dating types.

To aid the transparency of data reporting, every entry in the archeomagnetic and volcanic database is assigned a unique identification number (UID). UIDs will remain the same throughout the life of the database and indicate the order of the upload of entries through time, i.e., UID = 1 was the first entry uploaded to GEOMAGIA50.

A similar approach has been taken with the sediment data; however, a more sophisticated scheme has evolved to cater for the five results tables and the much larger number of entries compared with the archeomagnetic and volcanic database. The UIDs for the different results tables follow the format: $\mathrm{ABC}-\mathrm{Xnnnnn}$, where $A B C$ is the three letter location code of the sediment location (http://geomagia.gfz-potsdam.de/ID_ glossary.php\#SedLocCode), $\mathrm{X}$ is replaced by an abbreviation for the type of results table (C - individual (specimen/stratigraphic); S - processed (averaged/smoothed); D - radiocarbon ages; A - general ages; R - reconstructed), and nnnnn is the number of the entry (up to 99999). For example the first entry in the Lake Keilambete individual (specimen/stratigraphic) results table is KEI-C00001.

UIDs have previously been used in Donadini et al. (2009) to denote specific entries that were excluded for the modeling of Korte et al. (2009). In contrast to previous versions of the database they are now visible to the user. The UID allows the user to see the order of upload and quickly identify that an entry is unique when processing a large amount of data. If data from GEOMAGIA50 are used in future modeling efforts or in another form of analysis and certain data are excluded from the modeling or specific data require discussing, then the UID provides a brief and unambiguous way to communicate this information. Other users can use the UID to quickly relocate the data referred to in a publication within the database. In addition, if a user finds an error within an entry, this is the most efficient way to report a problem to a member of the database team.

\section{Archeological and volcanic data types}

The data within GEOMAGIA50 can be broadly classed into three types:

1. Paleomagnetic data;

2. Chronological data;

3. Metadata.

GEOMAGIA50.v1 and v2 contained the above data types from two categories of materials: archeological and volcanic (e.g., lavas, ash deposits, and pyroclastic deposits). GEOMAGIA50.v3 has been expanded to include paleomagnetic, rock magnetic, chronological, and metadata obtained from lake and marine sediments deposited over the past $50 \mathrm{ka}$. These data are described fully in Brown et al. (2015). The following subsections focus solely on data acquired from archeological and volcanic materials.

\section{Paleomagnetic data}

Archeological and volcanic materials have the potential to acquire a natural remanent magnetization (NRM) that is thermal in origin (termed a thermal remanent magnetization or TRM). TRM is obtained on cooling through a material's Curie-temperature (Néel temperature) to room temperature and can be preserved over geological timescales depending on the magnetic grain size distribution of a particular material. A TRM can be treated as the summation of blocks of magnetization associated with discrete temperature ranges (called partial TRM or pTRM). In the laboratory it is possible to reverse the magnetization process (demagnetization). By repeatedly heating a material carrying a TRM in a zero-field to increasing temperature steps, pTRMs can be demagnetized and the magnetization history of the material can be recovered. After each temperature application, the magnitude of three orthogonal components of magnetization can be measured at room temperature. If the material records a direction representative of a spot reading of the geomagnetic field (without secondary contamination), the components of magnetization will linearly decrease to zero with increasing temperature and a characteristic remanent magnetization (ChRM) direction (represented as declination and inclination) can be calculated for a particular temperature step or across a range of temperature steps.

As an alternative to heating, materials can be demagnetized by applying an alternating field (AF). Archeological and volcanic materials may contain a range of magnetic grain sizes, which can be demagnetized with different alternating fields. In a similar approach to thermal demagnetization, an AF can be increased in steps and if the resulting magnetization at each increasing $\mathrm{AF}$ step decreases linearly to zero, a ChRM inclination and declination can be calculated.

As discussed in 'General structure of the MySQL database' section, paleomagnetic data within the database are reported at the site level, i.e., at a level where the magnetization recorded by a material/medium/stratum/ geological unit can be assigned a unique age. If more than one specimen was used to estimate the direction or paleointensity (see below) of a site, as is common, the data in this entry will be a mean. If a mean was reported in a publication, this value is included in the database. If a mean was not published, yet multiple specimen or sample data were available, then a mean was calculated following Fisher (1953) and this is the value reported in the database. 
There is no method prerequisite for the mean directional data included in the database. Mean directions are most commonly calculated from specimens demagnetized by thermal and AF methods, with specimen directions determined from either a single demagnetization to a certain temperature or AF step, or from a fit to stepwise demagnetization data, e.g., by principal component analysis (Kirschvink 1980). Mean directions are frequently calculated using the statistics of Fisher (1953), however, mean directions calculated by any method are listed in the database. The distribution of inclination and declination data over the past $50 \mathrm{ka}$ is shown in Figure 3.

In addition to recording the direction of the field, a TRM can preserve an intensity proportional to the past
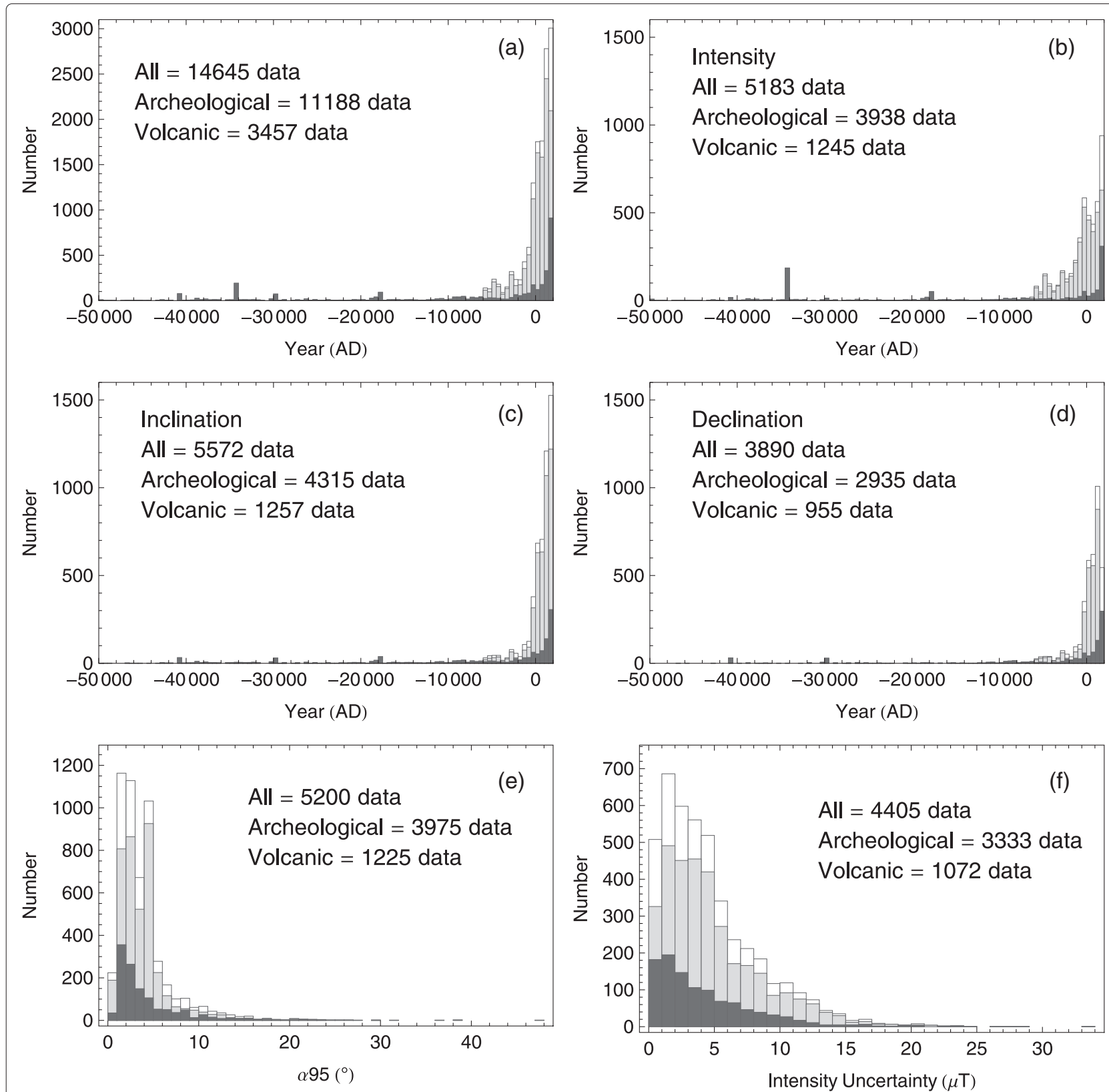

Figure 3 Distributions of archeological and volcanic data over the past $50 \mathrm{ka}$. (a-d) Data distribution through time in 500 year bins comparing archeological and volcanic sources for (a) all data, (b) intensity, (c) inclination, and (d) declination. (e) Distribution of $\alpha_{95}$ in $1^{\circ}$ bins and (f) intensity uncertainties in $1 \mu \mathrm{T}$ bins. White bars show all data, light gray show archeological data only and dark gray show volcanic data only. The numbers of specific data types are noted on the graph labels. There are less data for the intensity uncertainties than for the intensities as not all intensity data has been reported with an associated uncertainty. 
strength of the geomagnetic field (termed paleointensity). A variety of methods based upon different principles can be used to experimentally estimate paleointensity. See the 'Paleointensity metadata' section for a brief description of these methods as they relate to the paleointensity metadata stored in the database. See Valet (2003), Tauxe and Yamazaki (2007), and Dunlop (2011) for more detailed reviews of paleointensity methods. In brief, all paleointensity methods replace the NRM, either as a whole or in part, with a full TRM or pTRMs acquired in a known laboratory field. Assuming the relationship between the strength of magnetization of the removed NRM and the acquired TRM is directly proportional to the ancient field divided by the laboratory field, the ancient field can be estimated by multiplying the ratio of NRM to TRM by the strength of the laboratory field.

In practice, there are a number of complicating factors that can make the relationship between NRM and TRM nonlinear and/or nonproportional to the ancient field. This can depend in part on the paleointensity method chosen. Such factors include the influence of multidomain (MD) grains, thermal alteration during heating, acquisition of a thermochemical remanent magnetization (TCRM) on cooling in nature (e.g., Kellogg et al. 1970; Nagata and Kobayashi 1963; Yamamoto et al. 2003), differences between cooling rates in nature and the laboratory, remanence anisotropy, and non-linear acquisition of TRM with increasing applied field (see Perrin et al. (1998); Valet (2003); Tauxe and Yamazaki (2007); Fabian and Leonhardt (2009) for overviews of the majority of these issues). These problems can result in ambiguity in interpreting paleointensity experiments and may lead to significantly inaccurate estimates of paleointensity. A number of checks and/or corrections have been developed to address these issues, and the database accommodates metadata related to the most significant of these methods ('Paleointensity metadata' section).

Paleointensity estimates obtained using any paleointensity method are listed in the database; however, only metadata from certain methods accompany these data (see the 'Paleointensity metadata' section). Mean paleointensities can be statistically calculated in a variety of ways and these are not always clearly reported in the literature. Means may be arithmetic or weighted and several different weights can be applied (e.g., Coe et al. (1978); Prévot et al. (1985)). The reader is advised to check a specific publication to determine the method used to calculate a mean. It is not currently documented in the database. If mean paleointensities were not calculated in a publication, then we calculated an arithmetic mean from the reported specimen or sample intensity and this is the value reported in the database. The distribution of intensity data over the past $50 \mathrm{ka}$ is shown in Figure 3.
In addition to paleointensity, corresponding values of virtual dipole moment (VDM) and virtual axial dipole moment (VADM) are accommodated in the database. As the intensity of the geomagnetic field, when in a dipole configuration, is latitude dependent, intensity values obtained from different latitudes can not be compared easily. By assuming a dipolar structure, VDMs and VADMs allow comparison of global intensity values. A VADM has the equivalent moment of a magnetic dipole aligned with Earth's rotation axis for a measured intensity at a given latitude (see equation (1) in K08). In comparison, a VDM is calculated using magnetic colatitude estimated from a measured inclination, rather than site latitude, to allow for tilt in the dipole axis. However, non-dipolar fields (as noted in models of the Holocene geomagnetic field) are likely to contribute to the difference between an instantaneous measurement of inclination and the inclination expected from a dipolar field at the measurement site. If values of VADM and VDM are not reported in a publication, we have used the mean intensity data and either the site latitude to calculate a VADM or the mean inclination to calculate a VDM. Inclination does not accompany all intensity values in the database; however, every entry has a latitude. Therefore, there are a far greater number of VADM values (over 5,000) in the database than VDM values (approximately 1,700).

Uncertainties on paleomagnetic data are critical to the interpretation of past geomagnetic field behavior and to the construction of geomagnetic field models. Published mean directions are commonly accompanied by a measure of the angular dispersion of the specimen directions, $\alpha_{95}$, and an approximate measure of the precision of the mean direction, $k$ (Fisher 1953). $\alpha_{95}$ and $k$ are reported as given in a publication or if not given, calculated from specimen or sample directions, following Fisher (1953). Over $90 \%$ of directional entries in the database have an associated $\alpha_{95}$ value. These range from almost $0^{\circ}$ to over $45^{\circ}$ (Hammo Yassi 1987), with a median of $3^{\circ}$ (Figure 3).

Published uncertainties on paleointensities are taken at face value and reported in the database as given in the publication. Uncertainty is most commonly reported at one standard deviation; however, some publications list uncertainties at two standard deviations or as standard errors. We have not recalculated these uncertainties. Furthermore, in some cases, it is not clear how the uncertainty has been calculated. In all cases, the reader is referred to specific publications for further information as the type of uncertainty is not currently stored in the database. For entries where we have calculated a mean paleointensity, the associated uncertainty is one standard deviation. Approximately $85 \%$ of intensity estimates have some form of associated uncertainty, ranging from almost $0 \mu \mathrm{T}$ to approximately $33 \mu \mathrm{T}$, with a median of $3.7 \mu \mathrm{T}$ (Figure 3). Uncertainties on VDM and VADM 
are reported as in the literature, unless calculated by us, in which case the uncertainty of the mean paleointensity estimate was converted to VDM or VADM.

\section{Chronological data}

An independent knowledge of the ages of archeomagnetic and volcanic materials is vital for constructing, e.g., models of the geomagnetic field or archeomagnetic reference curves used for dating of archeological materials. Furthermore, the uncertainties reported with ages are useful in weighting the reliability of age data and provide greater flexibility in interpreting past changes of the geomagnetic field.

An age in years $\mathrm{AD}$ is reported with every entry in the database. Age data are asymmetrically distributed through time (Figure 3). Approximately $60 \%$ of data have an age younger than $0 \mathrm{AD}$ ( $4 \%$ of the total age range). Only approximately 600 entries are older than 10,000 BC and these are dominated by volcanic data. For younger ages, there are a far greater number of archeomagnetic than volcanic data (Figure 3).

Depending on the dating method, different statistical approaches can be used to give a point estimate of age and an uncertainty. It is out of the scope of this paper to review the nuances of age and uncertainty calculations for specific dating methods (Walker (2005); Taylor and Bar-Yosef (2014) provide recent overviews of quaternary dating methods); however, we briefly discuss the chronological metadata included in the database in the 'Chronological metadata' section. Furthermore, as the majority of experimentally determined ages are from radiocarbon dating ('Chronological metadata' section) we give a brief overview of the issues surrounding radiocarbon dating and how they have driven the reporting of ages and their uncertainties in the database.

Broadly, radiocarbon ages may be uncalibrated or calibrated and this determines how the age and its uncertainty have been reported. Uncalibrated radiocarbon ages are experimentally determined either by radiometric (often termed classical) or accelerator mass spectrometer (AMS) methods and are referred to as conventional ages. Following Stuiver and Polach (1977), the age and its uncertainty are calculated from the statistical distribution of ages based upon classical decay counting or AMS ion counting. The uncertainty may contain additional error from a variety of sources related to the dating measurement. Uncertainty is commonly reported at one standard deviation as recommended by Stuiver and Polach (1977); however, not in all cases, and the reader is referred to the publication where the uncertainty is reported if there is doubt over the uncertainty level.

As a result of changes in atmospheric carbon through time (de Vries 1958; Reimer et al. 2009) the conventional age is not representative of the true age of the material. The measurement of atmospheric ${ }^{14} \mathrm{C}$ in tree rings, and for older times through dating of macrofossils (e.g., from Lake Suigetsu (Bronk Ramsey et al. 2012)), has enabled the development of atmospheric radiocarbon calibration curves. These curves have been refined considerably since the first curves in 1970s (e.g., Clark 1975, 1979; Suess 1970), with the most recent curves, such as IntCal13 (Reimer et al. 2013) allowing calibration back to $50 \mathrm{ka}$. Changes in atmospheric radiocarbon through time are not simply linear, but vary unevenly. When the normal distribution of the conventional age is transformed across the undulating calibration curve, a multimodal probability distribution results. It is a non-trivial task to provide a point estimate of age and a measure of uncertainty from this multimodal distribution (see reviews by Michczyński et al. (2007); Telford et al. (2004)). Intercepts, means, weighted means, modes, and medians are all reported in the literature and the uncertainty may be the minimum and maximum ages at one or two standard deviations or reduced to a symmetrical uncertainty around the point estimate. Furthermore, some time periods are particularly problematic for dating as the flatness of the calibration curve results in a large range of possible ages, e.g., the Halstatt plateau (van der Plicht et al. 2004). To accommodate the asymmetrical nature of radiocarbon uncertainties, they are documented in two fields, a negative uncertainty $\left(\sigma_{- \text {ve }}\right)$ and a positive uncertainty $\left(\sigma_{+\mathrm{ve}}\right)$. The database also lists the type of age uncertainties $\left(\sigma_{\mathrm{ID}}\right)$ (http://geomagia.gfz-potsdam.de/ID_ glossary.php\#AgeErrorID).

\section{Metadata}

The following subsections describe the general, paleomagnetic, and chronological metadata accommodated by the database and the rationale for their inclusion.

\section{General metadata}

General metadata can be split into two kinds: (1) those related to paleomagnetic and chronological data, and (2) those associated with how these data are stored within the database. General metadata related to the paleomagnetic and chronological data include:

1. the source of the data, e.g., the publication or compilation the data were acquired from;

2. the geographical location of archeological or volcanic materials;

3. names/identifiers assigned to archeological or volcanic materials;

4. the types of archeological or volcanic materials;

5. the specimen type.

Data sources are discussed in detail in the 'Archeological and volcanic data sources' section. Geographic metadata at different levels are accommodated within the 
database, allowing greater specificity compared with previous versions of GEOMAGIA50. As in versions 1 and 2 of the database, every entry is assigned a latitude and longitude and a 'Country/Region ID' (Additional file 1: Table S1). Latitude and longitude are reported to the number of decimal places given in a publication. 'Country/Region ID' links to a metadata table containing the country/region, the latitude and longitude of the geographic center of the country/region, and the continent the data in an entry are from. The contents of this metadata table are listed at http://geomagia.gfz-potsdam.de/ ID_glossary.php\#CRID. The latitude and longitude in this table are used to calculate curves from a series of geomagnetic field models (described in Additional file 1), if the user elects to query by country/region ('Querying the database: the 'archeomagnetic and volcanic data' query form' section). Two new fields available in version 3 are 'Location Name' and 'Site Name' (Additional file 1: Table S1). 'Location Name' is the broader of the two. It lists the name of, e.g., an archeological excavation/site, a volcano or a specific location on a volcano which contains more than one site, such as for the HSDP project on Kilaeau volcano, Hawaii Island. 'Site Name' lists the name of a material that can be found at a location and assigned a unique age, e.g., a pot, a layer at an archeological excavation, or a lava flow.

To reduce ambiguity between what is retrieved by the user from the database and the data listed within a publication, the field 'Pub. Data ID' (publication data ID, Additional file 1: Table S1) has been added in version 3. 'Pub. Data ID' is a specific code assigned by the author of a study to an entry within a publication table. For instance, in Kapper et al. (2014) Table three, each fireplace was assigned a code (e.g., FA39) and this code is entered in 'Pub. Data ID.

Currently 42 material types are listed in the database (http://geomagia.gfz-potsdam.de/ID_glossary.php\#

MatID). The type of material may bias, or result in greater scatter of, estimates of direction (e.g., Castro and Brown (1987); Pavón-Carrasco et al. (2014c)) and intensity (see discussions in Donadini et al. (2007); Suttie et al. (2011); Ziegler et al. (2008)). The inclusion of different material types allows any researcher to investigate the general suitability of different material types for paleomagnetic analysis or refine searches to look for, or exclude, data from a particular material. We have broadly split materials into archeological and volcanic and these two categories are listed in the magnetic data results table ('Archeo/volcanic', Additional file 1: Table S1). This distinction is based upon composition (for example, lavas have naturally complex mineralogy that are varied and vastly different to fired clay) and to possible differences in the paleomagnetic results obtained by archeological and volcanic materials (see references above). The majority of material types listed in the database are archeological. Currently, only three are volcanic: lavas, volcanic ash deposits, and 'other or unspecified volcanic'. The online list will be updated as new materials are included.

Paleomagnetic measurements can be made on specimens of different size and shape. The database notes five different specimen types (standard cylinders, standard cubes, mini-samples or chip, single crystals, and large samples) and lists whether the specimen type was not specified. The user can select data based upon the type of specimen ('General constraints' section). Standard cylinders are defined as having a diameter of $25.4 \mathrm{~mm}$. Mini-samples are considered to be cylinders with a diameter less than that of a standard cylinder, e.g., $12 \mathrm{~mm}$ (Böhnel et al. 2009) or $5 \mathrm{~mm}$ as used in microwave systems (e.g., Hill and Shaw (1999)). Böhnel et al. (2009) found comparable accuracy between directions obtained between standard cores and 12-mm mini-samples. The 5$\mathrm{mm}$ specimens used in microwave analysis do not allow precise orientation and are not used to estimate paleomagnetic directions. Researchers may have a preference for a particular kind of specimen and it is therefore useful to delimit by type, e.g., if the user wishes to find all results using the single crystal method (Cottrell and Tarduno 1999). Some researchers prefer large samples (1 to $2 \mathrm{~kg}$ ) as they provide a more representative magnetization (e.g., Arrighi et al. (2004); Thellier (1977)), compared with standard paleomagnetic cylinders or smaller. In some cases, small samples may have issues with orientation and overprints resulting from drilling induced magnetization (Genevey et al. 2002).

The general metadata related to how the paleomagnetic and chronological data are stored within the database are the UIDs (see 'General structure of the MySQL database' section) and the month and year of upload. These fields are newly available in version 3 . As queried data are always ordered by the age of the site rather than in order of the upload, it was not previously possible to know which data were most recently added in versions 1 and 2 of the database.

\section{Paleodirectional metadata}

Accompanying mean inclination, declination, $\alpha_{95}$ and $k$ are metadata on the number of samples used to calculate a mean direction (' $\mathrm{N}_{\mathrm{dir}}$.'), the number of specimens measured for the directional analysis (' $n_{\text {dir. }}$ meas.'), the number of specimens accepted for the calculation of a mean direction (' $\mathrm{n}_{\text {acc. }}$ meas.'), the methods used for demagnetization ('Dir. Method', listed at http://geomagia.gfz-potsdam. de/ID_glossary.php\#DirMethID) and the maximum AF ('Max. AF') and maximum temperature ('Max. Temp') used for demagnetization, if $\mathrm{AF}$ and thermal methods were used (Additional file 1: Table S1). 


\section{Paleointensity metadata}

The database currently includes 12 method entries (http:// geomagia.gfz-potsdam.de/ID_glossary.php\#PIID). These include the Thellier method (Thellier and Thellier 1959) and a number of variants (Aitken et al. 1988; Coe 1967b), the two specimen method (Domen 1977), the IZZI protocol (Yu et al. 2004), and the quasi-perpendicular protocol (Biggin et al. 2007). Variants upon these methods are not noted explicitly, e.g., the MT4 protocol of Leonhardt et al. (2004a) is listed as being a Coe (1967b) method as it employs zero field heating steps before the in-field steps as in Coe (1967b). Other methods based upon Thellier double heating principles are classed as 'Other double heating', e.g., the method of Walton (1977). We accommodate Microwave variants of the (Thellier and Thellier (1959) and Coe (1967b) protocols (e.g., Hill and Shaw 1999; Shaw et al. 1996, which we call 'Microwave double heating') and the microwave variant of the perpendicular method (Kono and Ueno 1977; Thellier 1941), called 'Microwave single heating' (see Hill and Shaw (2007)). Suttie et al. (2010) provides a discussion on the physical basis of microwave demagnetization.

Methods based upon different underlying principles to the Thellier-type methods are also included: (1) the Shaw (1974) technique and variants of, e.g., Evans (1986); Rolph and Shaw (1985); Tsunakawa and Shaw (1994); Yamamoto et al. (2003); (2) the multispecimen parallel differential pTRM method (Dekkers and Böhnel 2006) and variants (Fabian and Leonhardt 2010); (3) the continuous high-temperature triaxe method (Le Goff and Gallet 2004) based upon the method of Boyd (1986); and (4) the method of Tanguy (1975), which incorporates alteration correction. The user can select whether to query for data obtained from Thellier-type and other heating methods (excluding Shaw derivatives), Shaw-type methods, and microwave methods ('General constraints' section). Data from other methods, such as the Wilson method (Muxworthy 2010; Wilson 1961), the van Zijl method (van Zijl et al. 1962), and the Preisach method (Muxworthy and Heslop 2011) are currently not included in the database, but can be accommodated in future revisions.

Obtaining paleointensity from archeological and volcanic materials is beset with problems. During paleointensity experiments, two issues have commonly been observed: (1) physicochemical alteration of a specimen on heating causing a change in its magnetic properties and (2) the influence of grains that are not noninteracting uniaxial single domain (SD), e.g., MD grains, and therefore do not follow the behavior predicted by SD theory (Néel 1949). Additional steps have been incorporated in the design of paleointensity experiments to monitor changes in magnetization resulting from these two problems.
Monitoring the influence of alteration depends on the method. In variants of the Thellier and Thellier (1959) method, either thermal or by microwave excitation, repetition of lower temperature in-field steps can be used to assess whether alteration has occurred. If the magnetization acquired between the initial heating step and the repeated step is significantly different, the specimen is thought to have altered. These steps are commonly referred to as pTRM checks (see Tauxe and Yamazaki 2007 for a fuller explanation). It is noted in the database whether pTRM checks have been used and searches can be refined to select intensity data obtained only from experiments incorporating pTRM checks ('General constraints' section). However, when treated alone, positive pTRM checks do not guarantee the accuracy of the paleointensity data. At least three caveats to the effectiveness of pTRM checks have been noted. Firstly, failure of pTRM checks can result from MD grains (Biggin 2010) (checks for MD behavior are described later in this section). Secondly, pTRM checks may pass (and the relationship between NRM and PTRM remain linear) when alteration produces grains with blocking temperatures higher than can be assessed by the check. The NRM may be remagnetized, but alteration will not necessarily be visible in the pTRM checks (see Valet (2003)). In this instance, the demagnetization components of the NRM will not tend to zero, but will tend towards the laboratory field. Thirdly, inaccuracies can result from measurement noise in low NRM intensity specimens (Bowles et al. 2006) and additional experimental uncertainties (Paterson et al. 2012).

It has been proposed that the difference between the pTRM check and the initial PTRM can be used to correct for alteration (Valet et al. 1996) and some entries in the database have data corrected in this manner (e.g., Valet et al. (1998)). The alteration correction method of Walton (1990) applicable to Thellier-type measurements is noted in the database, although can not be searched for. Caution must be taken when correcting PTRM for changes in magnetization resulting from alteration (Perrin et al. 1998).

In some studies measurements of susceptibility before and after acquisition of each pTRM have been used to monitor alteration (e.g., Coe (1967a); Gonzalez et al. (1997)) or a propensity to alter has been inferred from differences in susceptibility on heating and cooling in temperature-susceptibility curves, with some studies using this as a pre-selection method (e.g., Hartmann et al. (2011)). Alteration assessed using susceptibility is noted in the database and paleointensity data be can chosen by whether susceptibility was used as an alteration monitor ('General constraints' section). However, it has long been noted that changes in susceptibility may not mimic alteration of the remanence carriers (Coe 1967a; Thellier 
and Thellier 1959). Remanence carriers may only comprise a small fraction of the total magnetic contribution and the proclivity of each fraction to alter may differ. This may result in specimens acceptable for paleointensity being excluded based upon changes in susceptibility (Coe 1967a) or specimens showing limited susceptibility change being unsuitable for paleointensity analysis (e.g., Kosterov and Prévot (1998)).

Other alteration monitors or corrections used in Thellier double-heating methods are not explicitly stated in the database (e.g., Burakov and Nachasova (1985)), but are classed as 'Other correction'. They can be used to refine the data search purely on the existence of some nonspecific form of check or correction ('General constraints' section).

Changes in anhysteretic remanent magnetization (ARM) may mimic changes in TRM and have been used to monitor alteration. In the Shaw (1974) method, AF demagnetized ARMs acquired before and after the application of the total TRM step are used to assess alteration. Furthermore, expanding upon the idea of Kono (1978), Rolph and Shaw (1985) used the ratio of the pre- and post-heating ARMs to correct for non-linear alteration of the TRM at the same AF steps. The Rolph and Shaw (1985) correction to Shaw (1974) data is noted in the database. However, the degree to which ARM can correct for alteration of TRM is unclear (Tanaka and Komuro 2000; Valet and Herrero-Bervera 2009). To test the applicability of the ARM correction, Tsunakawa and Shaw (1994) incorporated a second TRM step: the double heating test (DHT). This compares the first TRM with the second TRM corrected using the ratio of ARMs before and after the second heating. If the difference between the two TRMs is greater than the experimental error, it is assumed that the ARM correction does not fully correct or over corrects the paleointensity estimate. As with methods to correct for alteration during Thellier-type methods, this correction should be treated with caution, especially for cases when the ratio of the pre- and postheating ARMs is far from unity; however, this correction is a standard step in more recent applications of the Shaw (1974) method (e.g., Yamamoto et al. (2003)).

The presence of MD grains has long been known to cause a non-linearity between NRM lost and pTRM gained in Thellier-type experiments (Levi 1977). This results in a concave curvature on a standard Arai-Nagata plot (Nagata et al. 1963). This curvature is typically assessed visually; however, the degree of curvature can be quantified (e.g., Paterson 2011), allowing MD dominated specimens to be isolated and removed from further analysis. Whether curvature was observed is currently not noted in the database, but would be a useful addition in any future revision. However, substantial non-linearity may not always be appreciable on an Arai-Nagata plot, yet paleointensity results may be biased by the presence of MD grains (Riisager and Riisager 2001), as MD grains can result in additional effects that may influence the outcome of paleointensity experiments (see Dunlop (2011) and references therein). Unlike for SD grains, pTRMs held by MD grains are not independent. This can result in undemagnetized pTRM after zero-field heating, referred to as a high temperature thermal demagnetization tail. Building upon earlier work, Riisager and Riisager (2001) suggested the presence of high temperature thermal demagnetization tails could be monitored in the Coe-Thellier method by applying zero-field steps at the same temperatures as preceding in-field steps. If the zero-field step did not result in full demagnetization of the PTRM, then a thermal demagnetization tail remained (i.e. a difference in the NRM of the zero-field steps either side of the in-field step) and the paleointensity estimate could be rejected. They termed this a 'pTRM-tail check'. We note whether a tail check was performed, but it is not currently possible to restrict the database output for paleointensity experiments that incorporated this check. Additionally, one must be mindful that tail checks can be calculated in a number of ways (e.g., Leonhardt et al. (2004b); Yu and Dunlop (2003)) and different limits may have been placed on the statistical acceptability of the checks depending upon the study.

An alternative approach is to reduce the influence of MD grains. Low-temperature demagnetization (LTD) can be an effective method of removing MD remanence held by magnetite (e.g., Ozima et al. (1964); Yu et al. (2003)). Although rarely employed within Thellier-like experiments, as it is required after each heating step and the experiment is already lengthy, LTD is commonly used as a modification to the Shaw (1974) method (e.g., Yamamoto et al. (2003)). It is noted in the database whether this method was employed. Paleointensity data retrieved by the database can be limited to those obtained using the Shaw (1974) method with additional LTD and DHT steps ('General constraints' section).

For archeological materials, two further corrections are frequently applied: (1) for the difference between cooling rates in the laboratory and at the time of firing, e.g., for kilns; and (2) for remanence anisotropy. The TRM acquired by a material is related to the time it takes to cool coupled with its magnetic grain size distribution (see Biggin et al. 2013 and Ferk et al. 2014 and references therein for a history of the subject). If for noninteracting SD grains the difference between the natural cooling and laboratory cooling is different, then the fundamental equation relating the ratio of these two TRMs to the ratio of the ancient to laboratory field is violated and a correction to the paleointensity estimate should be attempted. Many fired archeological materials contain non-interacting SD particle assemblages and a strong 
cooling rate dependence has been demonstrated (e.g., Fox and Aitken (1980)). Two approaches can be used to correct for cooling rate: theoretically or experimentally. If the time taken to cool naturally is known or estimated and the grain size is assumed to be $\mathrm{SD}$, then non-interacting SD theory can be applied to calculate the difference in TRM acquired on cooling in the laboratory and after firing (e.g., Halgedahl et al. (1980)). As fired archeological materials are often thermally stable (resulting from acquiring their remanence originally from reheating), then it is possible to experimentally determine the cooling rate effect without the complication of altering the TRM (e.g., Genevey and Gallet (2002)). We note in the database whether either of these approaches have been applied and it is possible to restrict the database output to only paleointensity results corrected for cooling rate dependence ('General constraints' section).

For grains other than non-interacting SD, the effect could be much smaller or even negligible, e.g., for MD grains, and a correction may not be necessary (Biggin et al. 2013; Ferk et al. 2014). This may be the case for many volcanic rocks. In addition, although cooling of lavas can take (with the exception of the margins) a few days to months, cooling rate corrections have rarely been attempted. To assess cooling rate dependence, the specimen must be heated above the Curie temperature, and in volcanics, this often results in alteration. It is therefore not possible to obtain reliable measurements of the cooling rate effect on the TRM (unless, in some cases, performed in a controlled atmosphere). For finer grained rocks, e.g., volcanic glass, cooling rate can be an issue (Ferk et al. 2010; Leonhardt et al. 2006); however, it is dependent on the difference between the laboratory and natural cooling rates (Bowles et al. 2005).

Archeological materials manipulated by hand or machine can preferentially align magnetic grains within the material. This is common, e.g., in pottery, where clay is stretched and molded. This can result in anisotropy of the TRM, with an easy direction of magnetization within the shear plane of the material (e.g., Rogers et al. (1979)). This can significantly bias paleointensity estimates as the TRM acquired is dependent on the angle between the remanence direction and the laboratory field. Different experimental approaches can be taken to address remanence anisotropy. To minimize the angular difference, the specimen can be aligned so its NRM is parallel with the laboratory field during the paleointensity experiment (e.g., Fox and Aitken (1980); Rogers et al. (1979)). This can be technically difficult. Alternatively, remanence anisotropy can be described by a second rank tensor and the paleointensity corrected (Veitch et al. 1984). A series of TRM, ARM, isothermal remanance (IRM), or susceptibility measurements can be made after or at some point during a paleointensity experiment (Chauvin et al. 2000) to define the TRM ellipsoid; however, caution should be used when using an induced remanence other than a TRM (Chauvin et al. 2000). An anisotropy correction can be applied to paleointensity data obtained from any method. The type of anisotropy correction is noted in the database and listed at http://geomagia.gfz-potsdam. de/ID_glossary.php\#PIANID. Whether an anisotropy correction has been used is a selection criterion limiting the output of the database for all methods except the microwave method ('General constraints' section).

The number samples $\left(\mathrm{N}_{\mathrm{Ba}}\right)$ used in the calculation of a mean paleointensity, the number of specimens measured for paleointensity analysis ( $\mathrm{n}_{\mathrm{Ba}}$ meas.), and the number of specimens accepted ( $\mathrm{n}_{\mathrm{Ba}}$ acc.) for the calculation of the mean paleointensity are noted in the database. The minimum number of specimens required to produce a reliable estimate has been discussed (e.g., Biggin et al. (2003); Paterson et al. (2010)), see also Suttie et al. (2011). These metadata may aid future analyses in this topic. As noted in the 'Paleomagnetic data' section, the type of uncertainty reported on the mean is not currently listed in the database; however, if the user wishes to calculate, for example, the standard error of the mean as a measure of uncertainty rather than the standard deviation, the number of accepted specimens is required. The number of accepted specimens (or accepted samples, if the number of accepted specimens is not given) can be used to restrict the output of the paleointensity data ('General constraints' section); however, it is recommended to proceed with caution when selecting a cut-off.

\section{Chronological metadata}

Dating methods for archeomagnetic materials vary. They include historical documentation, archeological evidence such as typologically defined epochs, stratigraphic information, and a range of physical/chemical/environmental methods, for instance radiocarbon dating (for a review, see Aitken (1999)). Volcanic materials are primarily dated by isotopic methods, e.g., by K-Ar, ${ }^{40} \mathrm{Ar} /{ }^{39} \mathrm{Ar}$, and radiocarbon dating (see the 'Chronological data' section); however, more recent volcanic materials have been dated through historical observations. In total, 18 dating methods are accommodated in the database. They are listed at http://geomagia.gfz-potsdam.de/ID_glossary. php\#DatMethod.

Knowing the type of dating method can aid in assessing the reliability of an age, and the database allows the user to select data based upon specific dating types (see the 'General constraints' section). Unfortunately, approximately $30 \%$ of ages are from unspecified methods. Along with ages based upon archeological evidence (approximately 40\%), radiocarbon ages (approximately 15\%), and historical ages (approximately 10\%), these four categories account for approximately $95 \%$ of all age data. 
Archeological ages may not be described in detail within archeomagnetic publications and may relate only to a specific archeological period. This age will be represented within the database as the central age of the period with an uncertainty based upon the upper and lower age of the period. Caution must therefore be taken in using these data to construct a time series. In some cases (approximately $1 \%$ ) archeological and volcanic materials have been dated by matching their direction and intensity to an archeomagnetic dating curve or location-dependent output from a geomagnetic field model. This dating type is noted in the database (see 'General constraints' section) (for the construction of geomagnetic field models or for refining archeomagnetic dating curves, such data are not recommended).

For radiocarbon ages, the name of the sample given in the publication and the specimen code used by the radiocarbon dating laboratory are listed in the radiocarbon ages results table (Additional file 1: Table S2). The laboratory code commonly contains a three-letter code preceding a series of numbers. This code is an abbreviation for the laboratory and a list of these codes can be found at http://www.radiocarbon.org/Info/labcodes.html (last accessed 19/01/2015).

\section{Archeological and volcanic data sources}

At the time of writing, approximately 461 studies have reported paleomagnetic data with over 9,000 globally distributed archeological and volcanic entries covering the past $50 \mathrm{ka}$ (Figure 4). The earliest study is from 1959 (the seminal paper by Thellier and Thellier (1959)) and there have been an increasing number of studies per decade until 2000 (Figure 1). All archeomagnetic and volcanic data held in the database can be related to a published source or are traceable through previously published databases, and we have an almost complete repository of electronic and paper articles, bar some entries which have appeared only in other databases. For volcanic data, the sources are peer reviewed publications and $\mathrm{PhD}$ theses. Archeomagnetic data may additionally be published by national or independent archeological agencies in the form of archeological site reports, for instance by English Heritage in the UK (e.g., Linford (1995)). These data may not have been peer reviewed. Data entered in the database can come from a publication, if listed in tabular form, or directly from an author, e.g., if no table of data was given in a publication. In a limited number of cases where tables of data did not exist (mainly in some of the older publications), the data were digitized.

Data has additionally been obtained from a number of published archeomagnetic and volcanic data compilations or databases. In such cases, the reference of the original study is reported in the database and it is accompanied by a 'Compilation ID' indicating the database or compilation from which the data were obtained. This gives credit to previous studies which compiled data and avoids possible ambiguity between data reported in different compilations.

Twelve databases and compilations are merged into GEOMAGIA50:

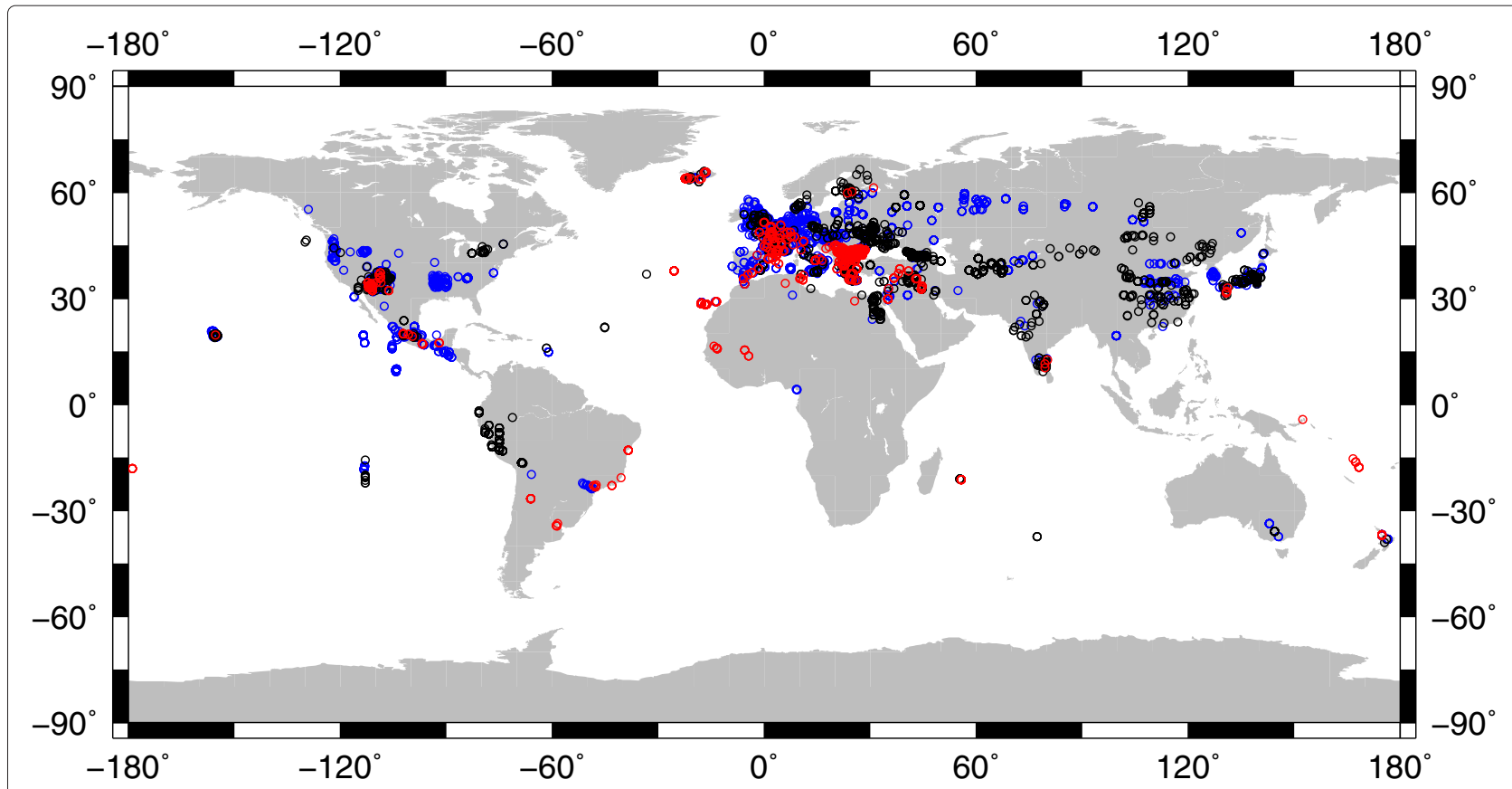

Figure 4 Locations of archeomagnetic and volcanic data added in GEOMAGIA50.v1 (black), GEOMAGIA50.v2 (blue), and GEOMAGIA50.v3 (red). 
1. The IAGA ARCHEO00 database (http://www.ngdc. noaa.gov/geomag/paleo.shtml) compiled by Don Tarling, University of Plymouth. No specific publication accompanies this database. The majority of data are from previously published sources (peer reviewed journals or from archeological site reports); however, a small number of entries are listed as unpublished. Data from 68 studies totalling 1,425 entries are included in GEOMAGIA50 from ARCHEO00.

2. The volcanic paleointensity database of Perrin and Schnepp (2004): 394 entries from 36 studies.

3. The historical directional compilation of Lanza et al. (2005) for lavas from Mount Vesuvius and Etna: 52 entries from six studies.

4. The volcanic and archeological directional and intensity compilation of Korte et al. (2005): 6,266 entries from 251 studies.

5. The compilation of Spanish archeomagnetic data of Gómez-Paccard et al. (2006b): 57 entries from seven studies.

6. The Hungarian archeomagnetic directional compilation of Márton and Ferencz (2006): 32 entries from one publication.

7. The Austrian archeomagnetic dating curve compilation of Schnepp and Lanos (2006), which includes data from Austria, Bosnia, France, Germany, Hungary and Switzerland: 47 entries from six studies.

8. The compilation of Italian archeomagnetic directions of Tema et al. (2006): 70 entries from ten studies.

9. The UK archeomagnetic directional compilation of Zananiri et al. (2007): 456 data from 31 studies.

10. The ArcheoInt compilation of Genevey et al. (2008): 3,338 entries from 150 studies.

11. The Sofia Laboratory, Bulgaria, archeomagnetic compilation of Kovacheva et al. (2009): 388 entries from 25 studies.

12. The revised Bulgarian archeomagnetic compilation of Kovacheva et al. (2014): 350 data from 21 studies.

The compilation IDs are listed at http://geomagia. gfz-potsdam.de/ID_glossary.php\#CompID and will be updated as new compilations appear. A number of these compilations are summarized in Table two of Donadini et al. (2009). The original compilation of Donadini et al. (2006) used in GEOMAGIA50.v1 contained 3,716 entries from 163 studies and this compilation is also noted with 'Compilation ID' 1006. In many cases, data appear in one or more compilations or databases. Care was taken to avoid duplicating entries from the different compilations. Compilation metadata are shown in the magnetic data results table ('Query results' section) when the 'Detailed' checkbox is selected from 'Abridged or detailed output' panel on the archeomagnetic and volcanic query form (Figure 5).

\section{Modifications and updates to the archeomagnetic and volcanic database Inclusion of directional data and newly published data}

GEOMAGIA50.v1 accommodated directional data only if coupled with paleointensity data. The usefulness of the database to select data for geomagnetic field modeling (e.g., Donadini et al. (2009); Korte et al. (2009)) led us to include additional archeomagnetic and volcanic directional data. Sites with directional data alone have been accommodated from GEOMAGIA50.v2 onwards.

To date, a total of 14,645 data have been obtained, comprising declination (3,890 data), inclination (5,572 data) and paleointensity data (5,183 data) from a total of 461 studies. This is an increase of 89 studies from GEOMAGIA50.v2, which contained 372, and 302 more than GEOMAGIA50.v1, which contained 159 studies. The full list of studies included in GEOMAGIA50.v3 can be found at http://geomagia.gfz-potsdam.de/studies.php.

Data are globally distributed (Figure 4); however, $95 \%$ of the entries are from the Northern Hemisphere. Figure 4 shows the change in the global distribution of sites between different versions of the database. Importantly, there has been an increase in data from central Africa, south America, southern India, and Oceania within version 3. Other additional data of note are from North America and Bulgaria. Several data from North America (reference ID 445 to 484) were revised and included in GEOMAGIA50 in 2011; approximately 150 data were added. The Bulgarian data set was recently updated by Kovacheva et al. (2014). Several dates and paleomagnetic data were revised, including studies published after Kovacheva et al. (2009). The newer, revised version of the Bulgarian data set is now available in GEOMAGIA50.v3 and these entries are noted with compilation ID 1012 ('Archeological and volcanic data sources' section). Data with this compilation ID may differ from those originally published.

\section{Dating}

As discussed in 'General structure of the MySQL database' and 'Chronological metadata' section, a new results table has been designed to accommodate experimental radiocarbon ages and their uncertainties. In versions 1 and 2 of the database, age uncertainties were reported in a single field giving $\pm \sigma$ age. We now report ages as a negative uncertainty $\left(\sigma_{-\mathrm{ve}}\right)$ and a positive uncertainty $\left(\sigma_{+\mathrm{ve}}\right)$, along with an ID for the uncertainty type $\left(\sigma_{\text {ID }}\right)$ (see rationale in 'Chronological data' section)

\section{Metadata}

In comparison to GEOMAGIA50.v1, which contained seven metadata tables (Figure one in K08) and displayed 11 metadata fields within the magnetic data results table (called 'Master Table' in section 5.2.1. of K08), version 3 


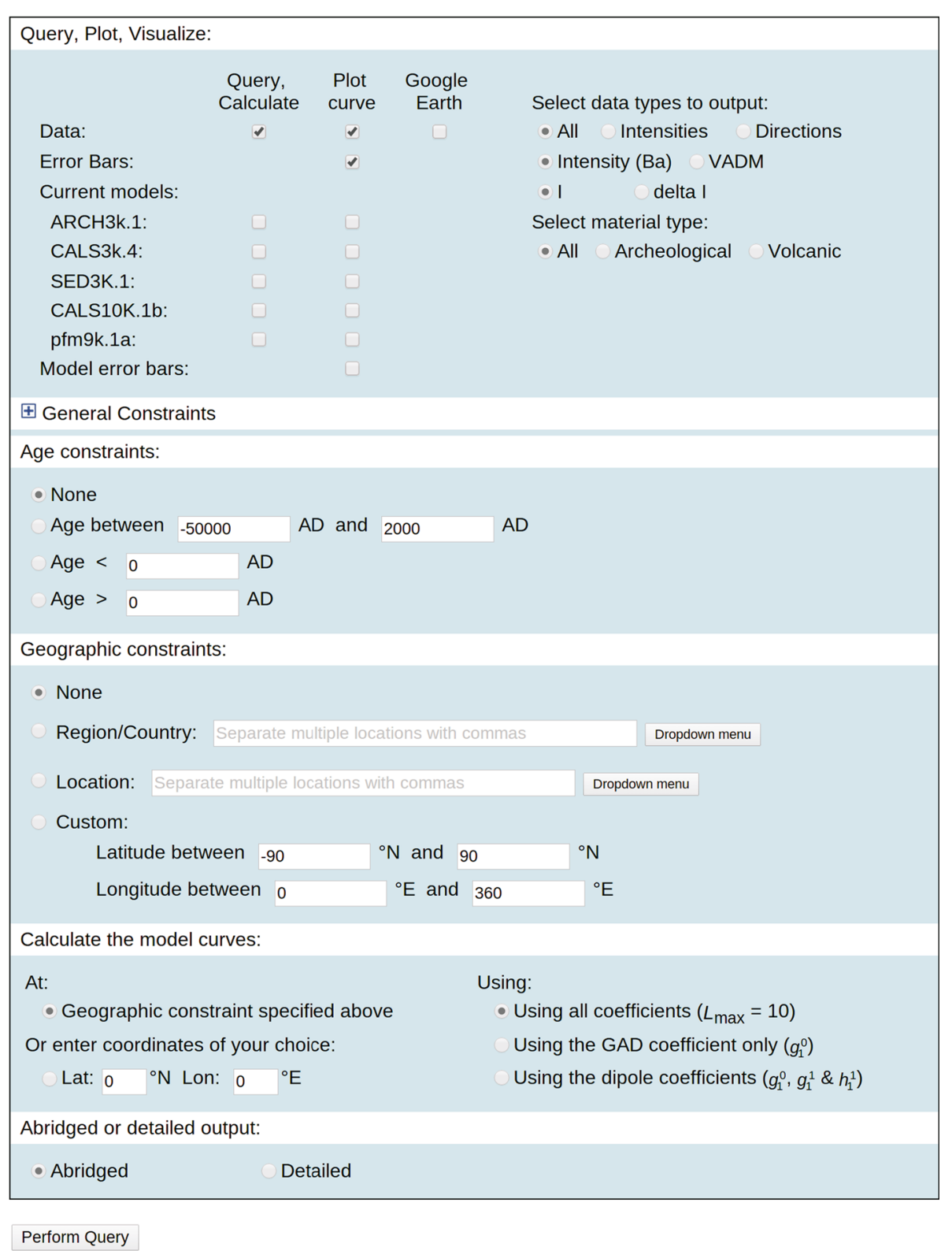

Figure 5 Initial state of the archeomagnetic and volcanic query form after the user has selected the 'Archeomagnetic and volcanic query form' link from the left navigation menu on the GEOMAGIA50 home page or entered http://geomagia.gfz-potsdam.de/geomagiav3/AAquery.php into a browser's address bar.

calls from 14 metadata tables and displays 30 metadata fields (Additional file 1: Table S1). The metadata tables shown in K08 have been appended with new entries and fields. The 'Country/Region' metadata table (previously called SITES in Table two of K08) now contains a field for continents. This allows ordering of countries/regions by continent in the dropdown menu in geographic constraints (Additional file 1: Figure S3). In addition, it has been appended with new countries/regions as data have been added in versions 2 and 3 of the database (and as data have been added to the sediment database (Brown et al. 2015), with which this metadata table is shared). Currently, their are 110 countries/regions. The most upto-date country/region metadata table can be found at http://geomagia.gfz-potsdam.de/ID_glossary.php\#CRID.

The metadata table for the types of archeological and volcanic materials ('General metadata' section) has been expanded from 15 (Table three in K08) to 42 .

The paleointensity metadata table has been simplified from Table four in K08. The table is now split into four metadata tables. The first table lists 12 broad 
method types ('Paleointensity metadata' section and http://geomagia.gfz-potsdam.de/ID_glossary.php\#PIID), instead of the 17 methods in K08. The alteration, cooling rate and anisotropy monitors/corrections ('Paleointensity metadata' section) previously listed in this table have been assigned their own metadata tables. In addition, metadata for MD checks have also been included ('Paleointensity metadata' section). These span five fields in the results tables ('Query results' section): 'PI Method ID', 'Alteration Monitor ID', 'Multi-domain Monitor ID', 'Cooling Rate ID', and 'Anisotropy ID' (Additional file 1: Table S1), rather than the one in version 1 . Therefore, the user should note the IDs listed in the output tables do not match Table four in K08.

In version 1, 13 dating methods could be assigned to each data entry, e.g., radiocarbon dating, thermoluminescence dating, or archeological information (Table five in K08). The number of dating methods has been expanded to 18 (excluding 'Not specified') (Figure 6), including, e.g., dendrochronology and new techniques such as rehydroxylation (Burakov and Nachasova 2013; Le Goff and Gallet 2014; Wilson et al. 2009) ('Chronological metadata' section).

The specimen types metadata table (Table six in K08) has been expanded to include large samples (http:// geomagia.gfz-potsdam.de/ID_glossary.php\#SpecID), such as preferred by Thellier (1977). The statistics table (Table seven in K08) is no longer used as the ranking system has been retired ('Ranking' section).

In addition to updating (or removing) existing metadata tables, a number of new metadata tables have been added. The three most important additions to the metadata available are as follows: (1) more detailed location information ('General metadata' section); (2) additional experimental information, such as the temperature and AF used in demagnetization ('Paleodirectional metadata' section) and the type of MD monitor used ('Paleointensity metadata' section); and (3) information on the database entry, including an ID for each entry (the UID; 'General struc ture of the MySQL database' section) and the month and year of upload ('General metadata' section). All fields in Additional file 1: Table S1 ending in ID (with the exception of 'Pub. Data ID', 'C14 ID', and 'UID') have an associated metadata table. A brief explanation of their purpose and links to the content of these tables are listed in Additional file 1: Table S1.

\section{Terminology}

To align GEOMAGIA50 with the MagIC database (Constable et al. 2006), we redefined some of the terms used within the database. The most important is the change in the use of geographical terms. In $\mathrm{K} 08$ what is defined as a site in GEOMAGIA50 is a location in MagIC. This partly stems from a difference in terminology in archeology and paleomagnetism. In archeology, it is common to refer to an excavation as a site; however, this may contain multiple temporally distinct units or artefacts. In paleomagnetism, the use of site usually denotes a cooling or geological unit that can be assigned a unique age and a collection of units would be a location.

\section{Data updates and error reporting}

Updates to the database, e.g., if new data have been added, will be listed on a log page (http://geomagia.gfz-potsdam. de/logs.php). Users are encouraged to cite the date of data download when referencing the database in their work. In addition, user feedback revealed some erroneous entries in versions 1 and 2. GEOMAGIA50.v3 includes corrections to these data and they are listed on the log page. A number of location errors and duplicates were corrected in 2008. The locations of some Greek sites were modified (see Tema and Kondopoulou (2011)); the new locations were kindly provided by Evdokia Tema and Javier PavónCarrasco (pers. comm.). Detailed cross-checking of the data is ongoing and corrections will be listed on the log page.

\section{Model predictions}

The development of GEOMAGIA50 has been closely linked to the data required to construct global spherical harmonic models of the Holocene geomagnetic field (e.g., Korte et al. (2011)). Additionally, it has become common to compare archeomagnetic, volcanic, or sediment data with the location-dependent output of these models (e.g., Haltia-Hovi et al. (2011); Kapper et al. (2014); Tanaka et al. (2012)). To ease such comparisons, we have incorporated functionality to plot and save model predictions for user defined locations ('Figures and downloads' section). A description of the available models is given in Additional file 1 and how to query them is given in section 'Query, plot, visualize' and in Additional file 1.

\section{Web site features}

In version 3, users have the option to search for data using a specific location rather than just a country/region (Figure 5), e.g., from specific archeological excavations or volcano. This provides a much greater level of flexibility in the geographical search. Additional metadata fields to accompany this location information ('General metadata' section) are shown in the magnetic data results table (Additional file 1: Table S1).

Visualization of data sites in Google Earth and a searchable list of studies are two new features of GEOMAGIA50.v2 onwards that allow a better overview of the available data. The aim of the visualization is to show the locations of archeomagnetic and volcanic sites within Google Earth, differentiate by data type (inclination, declination, and paleointensity) and by time, and is explained 


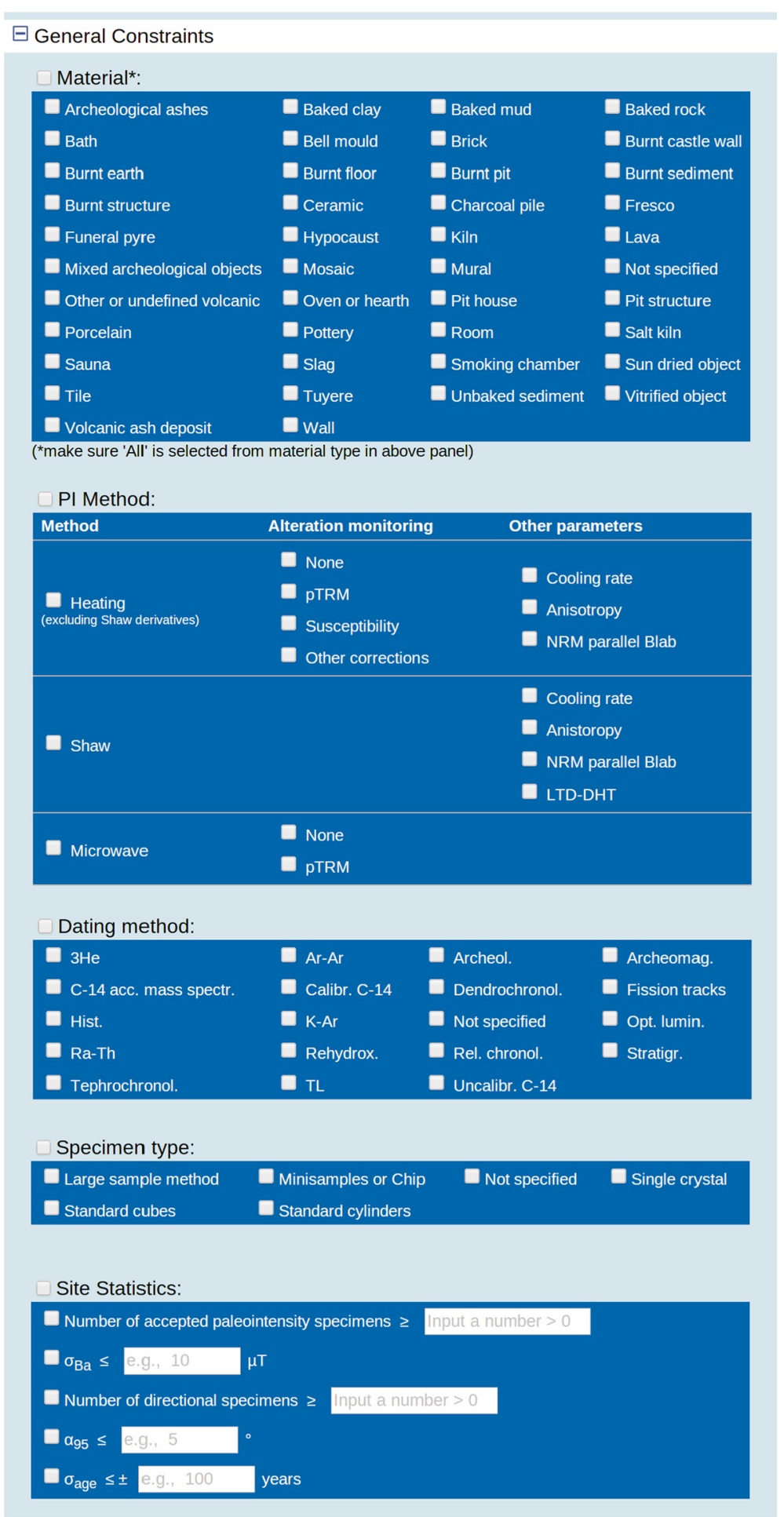

Figure 6 Initial state of the 'General constraints' panel within the archeomagnetic and volcanic query form.

further in the 'Google visualization' section. Maps of sites with inclination, declination, and intensity are also displayed at http://geomagia.gfz-potsdam.de/archeomap. php.
A reference list of all archeomagnetic and volcanic studies included in the database was introduced in version 1 and has been modified in version 3 . The list can be sorted according to ID, authors, publication year, or journal. 
Search boxes have been added in version 3 to allow users to search author and title fields, so that references related to a particular author or location can quickly be found. As in version 1, the list includes the volume and page information as well as a link to the reference record within the MagIC database, if it exists. Newly added in version 3 are hyperlinked DOIs, which allow users to find quickly the online location of the publication. However, these are not always available, notably for books and theses.

\section{Features no longer supported \\ Ranking}

Version 1 of the database (K08) aimed to rank numerically the reliability of paleointensity data based upon (1) the experimental method; (2) a specimen's material; (3) the type of specimen (e.g., cylinder or chip); and (4) the number of specimens measured. The ranking was based on a comparison of archeointensity results obtained using various materials and methods (Donadini et al. 2007). The ranks of the four groups were equally weighted and this subjective choice may not reflect the true reliability of the data. Ranking could be based only upon the data available. In a number of cases, there were insufficient data to rank the data and this may exclude sites that may accurately record the paleomagnetic field or produce sample groups too small to provide statistically meaningful comparisons. The ranking did not consider the selection of specimen level data, i.e., the use of a range of statistics to assess the quality of the paleointensity experiment (see, e.g., Paterson et al. (2014)), which may influence the site mean data.

Furthermore, there is still significant debate within the community regarding how the reliability of paleointensity data should be assessed and what approach should be taken when incorporating paleointensity data in global field modeling. We still lack an understanding of many aspects of the physical recording mechanism of remanence within archeological and volcanic materials and the processes that occur during paleointensity experiments. There may be unknown parameters that influence the outcome of the experiments that we are only now becoming aware of (e.g., Bowles et al. (2013)). It is an area of much active research. The ranking system was therefore removed from version 2 onwards. However, the flexibility of the 'General constraints' options ('General constraints' section) allows the user to select data based upon methods, materials, specimen types, and site statistics.

\section{Model visualization within Google Earth}

GEOMAGIA50.v2 included an option to visualize not only data ('Google visualization' section) but also global model predictions in Google Earth (Lodge and Korte 2009). However, the computational time required to plot the global geomagnetic field greatly increased the time taken to return search queries and has been removed in the most recent version 3 .

\section{User interface: GEOMAGIA50.v3 web page Querying the database: the 'archeomagnetic and volcanic data' query form}

The archeomagnetic and volcanic data query form (Figure 5) allows the user to constrain the output of the database by selecting different data, age, geographic, model, and column options. The web page is located at http:/geomagia.gfz-potsdam.de/geomagiav3/ AAquery.php. The form is divided into six panels:

1. Query, plot, visualize;

2. General constraints;

3. Age constraints;

4. Geographic constraints;

5. Calculate the model curves;

6. Abridged or detailed output.

The following sections describe briefly the options available to the user and their rationale. Additional file 1 contains a detailed user's guide to the different panels.

\section{Query, plot, visualize}

The options available in the top panel of the query form allow the user to select whether to (1) view query and download data, (2) plot data, (3) show error bars, (4) select different types of data to output, and (5) choose from different geomagnetic field models to query (Figure 5). A description of the available models is given in Additional file 1.

Data error bars are selected to plot by default as the uncertainties in direction, intensity, and age can often be non-trivial. It is not necessary to select the error bars check box to include uncertainties in the magnetic data results tables to download ('Figures and downloads' section); this is done by default. As discussed in the 'Paleomagnetic data' and 'Chronological data' sections, different types of uncertainties are listed in the database and the plots will show all uncertainties regardless of type. The model boot-strapped error estimates described in Additional file 1 can be plotted by selecting the model error bar check box below the list of models. This is possible for all models with the exception of the pfm9k.1a (Nilsson et al. 2014), for which no errors were calculated. The model uncertainties are listed in the output file (Additional file 1: Table S3) without requiring selection of the model error bars check box.

Four further options are available in the upper panel. These allow the user to refine the output of database search using broad data and material criteria. Under 'Select data types to output' the user can choose between three options: (1) whether to output (a) all data types 
(checked by default), (b) intensity data only or (c) directional data only; (2) whether to output intensity (Ba) in $\mu \mathrm{T}$ (checked by default) or have it converted to VADM ('Paleomagnetic data' section); and (3) to output inclination (checked by default) or the inclination anomaly (delta I).

VADMs are calculated using paleointensity and site latitude data stored in the database ('Paleomagnetic data' section). These are not values reported in the literature. The inclination anomaly is simply the difference between the measured inclination and the inclination of the geocentric axial dipole (GAD) at the site location. These values are calculated using the inclination and coordinate data stored within the database and are not published values. It is provided as a convenient means of comparing inclination data across the globe.

Under 'Select material' type the user can choose between (a) all materials, (b) archeological materials, or (c) volcanic materials. This provides a coarse distinction between the primary material types within the database ('General metadata' section).

\section{General constraints}

The 'General Constraints' panel allows the user to refine the data search using metadata constraints for (1) materials, (2) paleointensity methods ('PI Method'), (3) dating methods, (4) specimen types, and (5) statistics of the paleodirectional and paleointensity data (Figure 6). Justification for the inclusion of the metadata available to constrain the query is given in the 'Metadata' section.

The 'Material', 'Dating method', and 'Specimen type' panels simply allow the user to restrict the output of the database to the options available within the panels. The metadata themselves are explained in the 'General metadata' section and further information on their function can be found in Additional file 1.

The 'PI method' panel is split into a three by three grid. It contains a number of options to refine the data output based upon the paleointensity method (described in the 'Paleointensity metadata' section). Methods are grouped into three types and make up the three rows of the grid, with the method type shown in the first column. The upper row allows the user to return data from all heating methods, with the exception of the Shaw (1974) method. This includes all Thellier and Thellier (1959) derivatives, the multispecimen parallel differential pTRM method (Dekkers and Böhnel 2006), and variants (Fabian and Leonhardt 2010), the continuous high-temperature triaxe method (Le Goff and Gallet 2004) and the method of Tanguy (1975). The second row allows all variants of the Shaw (1974) method to be selected. The microwave method can be selected in third row.

The second column lists methods of alteration monitoring ('Paleointensity metadata' section) and the third column lists other monitors or corrections that were incorporated into the paleointensity experiment, such as cooling rate and anisotropy corrections ('Paleointensity metadata' section). If 'LTD-DHT' is selected in the second row, then only results using the Yamamoto et al. (2003) variant of the Shaw (1974) method will be returned.

The 'Site statistics' panel allows data to be restricted based upon the statistical properties of the directional and intensity data of an entry and the data's age uncertainty. The user can choose numerical limits. The number of accepted paleointensity and directional specimens can be entered ('General metadata' section), as can limits on the uncertainty of directional and paleointensity estimates and the age uncertainty ('Chronological data' section). The values given in the text boxes are merely illustrative of what could be entered (Figure 6). The 'Site statistics' panel was designed to aid user investigation of the database, not suggest these are the parameters one should use when deciding upon reliable data. For instance, the use of a $\mu \mathrm{T}$ cut-off could also be represented as a percentage (see Suttie et al. (2011) and Biggin and Paterson (2014) for discussions on this issue).

\section{Age constraints}

Time periods of varying durations may be of interest to the user and we provide four age constraint options (Figure 5). The user can return all data regardless of age; data between two selected ages; data older $(>)$ than a certain age; and data younger $(<)$ than a certain age. All ages are in years $\mathrm{AD}$. For years $\mathrm{BC}$, negatives should be entered.

\section{Geographic constraints}

The user can geographically constrain the output of the database using four options. These options have been designed to cater for the differing needs of the researcher. For global modeling of the geomagnetic field, the 'None' option allows all data to be returned. For the construction of country-dependent archeomagnetic reference curves, the 'Region/Country' option is most useful. If the user wants to find out what results exist for a specific archeological excavation or volcano, then the 'Location' option quickly returns these data. This can be useful in the investigation of the data scatter, e.g., in paleointensity estimates, from lava flows from a single volcano. Within the database, paleointensity estimates from lava flows of the same age are available that have been estimated using differing methods, e.g., the 1960 lava flow from Kilauea, Hawaii. By constraining the age and selecting 'Hawaii Island - Kilauea' from the 'Location' list, these data can be quickly recovered. The 'Custom' option is useful for returning data from more targeted regions, such as the Southern Hemisphere or around the equator, or for regions that contain many data, but span international borders, e.g., the 'Middle East' and Mediterranean. 


\section{Calculate the model curves}

This panel allows the user to investigate various components of the geomagnetic field models available to query and to select specific locations for generating model curves (Figure 5). As the models are created using a spherical harmonic expansion, the coefficients within the model can be isolated and can inform us about different contributions to the geomagnetic field. By default all coefficients (up to degree 10; Korte and Constable 2005) used in the modeling are selected. The user can choose to plot and download only the axial dipole term $\left(g_{1}^{0}\right)$ or the axial dipole term plus the equatorial dipoles $\left(g_{1}^{1}\right.$ and $h_{1}^{1}$ ), to assess the contribution of these terms to the model output.

\section{Abridged or detailed output}

Two forms of the magnetic data results table can be output. The abridged version is set by default and provides paleomagnetic data with age, coordinates, and the minimal number of metadata fields required to understand the data. The detailed version contains more substantial data, including location and site information ('General metadata' section); the results of the VDM calculation; details on the number of specimens and samples used in the calculation of the paleomagnetic data ('General metadata' section); information about the compilations the data were from ('Archeological and volcanic data sources' section); and information on the month and year of upload ('General metadata' section). The fields that are included in the detailed output are marked with asterisks in Additional file 1: Table S1.

\section{Query results}

A query is executed by clicking 'Perform Query' at the bottom of the query form (Figure 5). Once clicked, a new tab will be launched in the browser. This tab contains four additional on-page tabs (Figure 7). The first two tabs show the results tables for the magnetic data and radiocarbon age data ('Results tables' section). The third tab shows plots of the data and links to download the plots, the results tables and model output ('Figures and downloads' section). The fourth tab displays the Google visualization ('Google visualization' section).

\section{Results tables}

The 'Magnetic data' tab is split vertically into three sections: (1) a summary of the users query parameters (Figure 7); (2) the magnetic data results table (Figure 7); and (3) relational metadata tables describing the IDs within the magnetic data results table (Figure 8).

The 'Summary of query parameters' table outlines the selections the user made on the query form ('Querying the database: the 'archeomagnetic and volcanic data' query form' section). In addition, it shows warning messages to the user, flagging any irregularities in the constraints they have selected.

The magnetic data results table is a large twodimensional table with multiple fields and can contain multiple entries depending on the query selected by the user. The table is ordered by the age associated with the paleomagnetic data (oldest to youngest). All fields in the results tables are described in Additional file 1: Table S1. An abridged portion of a sample magnetic data results table showing data from Italy is shown in Figure 7. The table contains a number of metadata fields that list IDs (see the 'General structure of the MySQL database' section). Each ID is a hyperlink that when clicked scrolls down to a relational table describing the ID (Figure 8).

All the relational metadata tables (discussed in the 'General structure of the MySQL database' section) are found at the bottom of the tab below the magnetic data results table. Only metadata tables relevant to the available data shown in the magnetic data results table are shown, e.g., if only directions were queried by the user then the paleointensity metadata tables are not shown. Furthermore, each metadata table shows only the IDs related to data shown in the magnetic data results table. An example is shown for a location query of 'Michoacan Guanajuato Volcanic Field - Paricutin' (Figure 8).

The 'Radiocarbon age data' tab contains a single table briefly listing the experimental radiocarbon data and accompanying paleomagnetic data (Figure 9 and Additional file 1: Table S2). Each entry is linked to the 'Query results' table on the 'Magnetic data' tab through the field 'C14 ID' (as explained in 'General structure of the MySQL database' section).

\section{Figures and downloads}

The 'Figures and Downloads' tab shows a series of plots and lists hyperlinks to the results tables and model output that can be downloaded (Additional file 1: Figure S5). Up to three plots are shown if the user has elected to plot data. The plots will show declination, inclination or inclination anomaly, and intensity or VADM, depending on the options selected by the user. If error bars are selected to plot, then the uncertainties plotted on the directional graphs are $(81 / 140 \cos (\mathrm{I})) \alpha_{95}$ for declination (where $\mathrm{I}=$ inclination and $\alpha_{95}$ (Fisher 1953) is the directional uncertainty recorded in the database for an entry) and (81/140) $\alpha_{95}$ for inclination (Piper 1989). Intensity uncertainties are plotted as given in the magnetic data results table. If models are selected to plot, then the site-dependent output will be plotted alongside the data. An example plot showing intensity data and model predications for the past $10 \mathrm{ka}$ from Turkmenistan is shown in Figure 10. The figures are available to download as SVG files by clicking on the hyperlinks below the images (Additional file 1: Figure S5). 


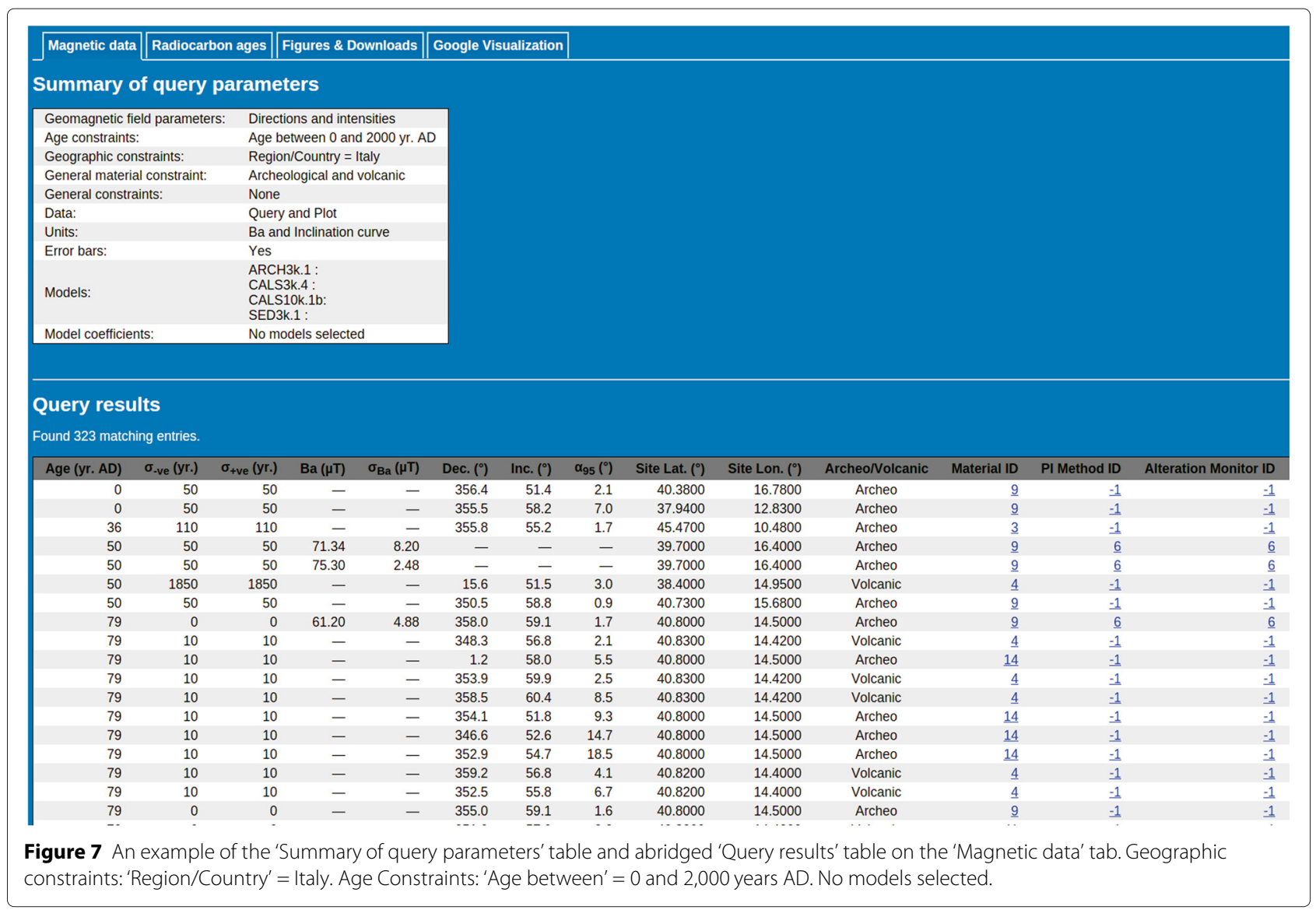

Two .CSV files containing the magnetic data and radiocarbon results tables and up to five .TXT files containing model output are available to download via hyperlinks (Additional file 1: Figure S5), depending on the data and models selected to query. The .CSV files contain the columns and data shown in the online magnetic data results and radiocarbon ages results tables. In the online tables, blank values are shown as -. In the .CSV files, this is replaced with -999 for directions, intensities and their uncertainties, and -1 for unspecified metadata. All the IDs found in the downloaded .CSV file are listed at http:// geomagia.gfz-potsdam.de/ID_glossary.php. The fields in the model output files are described in Additional file 1: Table S3.

\section{Google visualization}

When the 'Google Earth' check box is selected on the query form (Figure 5), a Google Earth map will be launched on the 'Google Visualization' tab (Additional file 1: Figure S6). All sites found using the country/region, location, or custom geographic constraints are marked on the map. In addition, a time bar allows the user to search through sites with time. Sites with declination, inclination, and intensity are shown with different symbols. When the site marker is clicked, a brief summary of the site results and metadata are given, including age, geographic coordinates, the reference ID, the UID, and the paleomagnetic result. The visualization coding is based on the work of Lodge and Korte (2009).

\section{Conclusion}

GEOMAGIA50.v3 is an updated version of the GEOMAGIA database originally described by Donadini et al. (2006) and Korhonen et al. (2008). The database's aim is to improve our knowledge of the geomagnetic field, archeology, paleoclimate, and past environments. The database has a web interface that allows users to search for paleomagnetic, rock magnetic, and chronological data spanning the past $50 \mathrm{ka}$. The interface can be found at http://geomagia.gfz-potsdam.de/ and is mirrored at http://geomagia.ucsd.edu.

In comparison to version 1 of the database, a number of improvements have been implemented. Most notable are the addition of sediment data, a greater number 


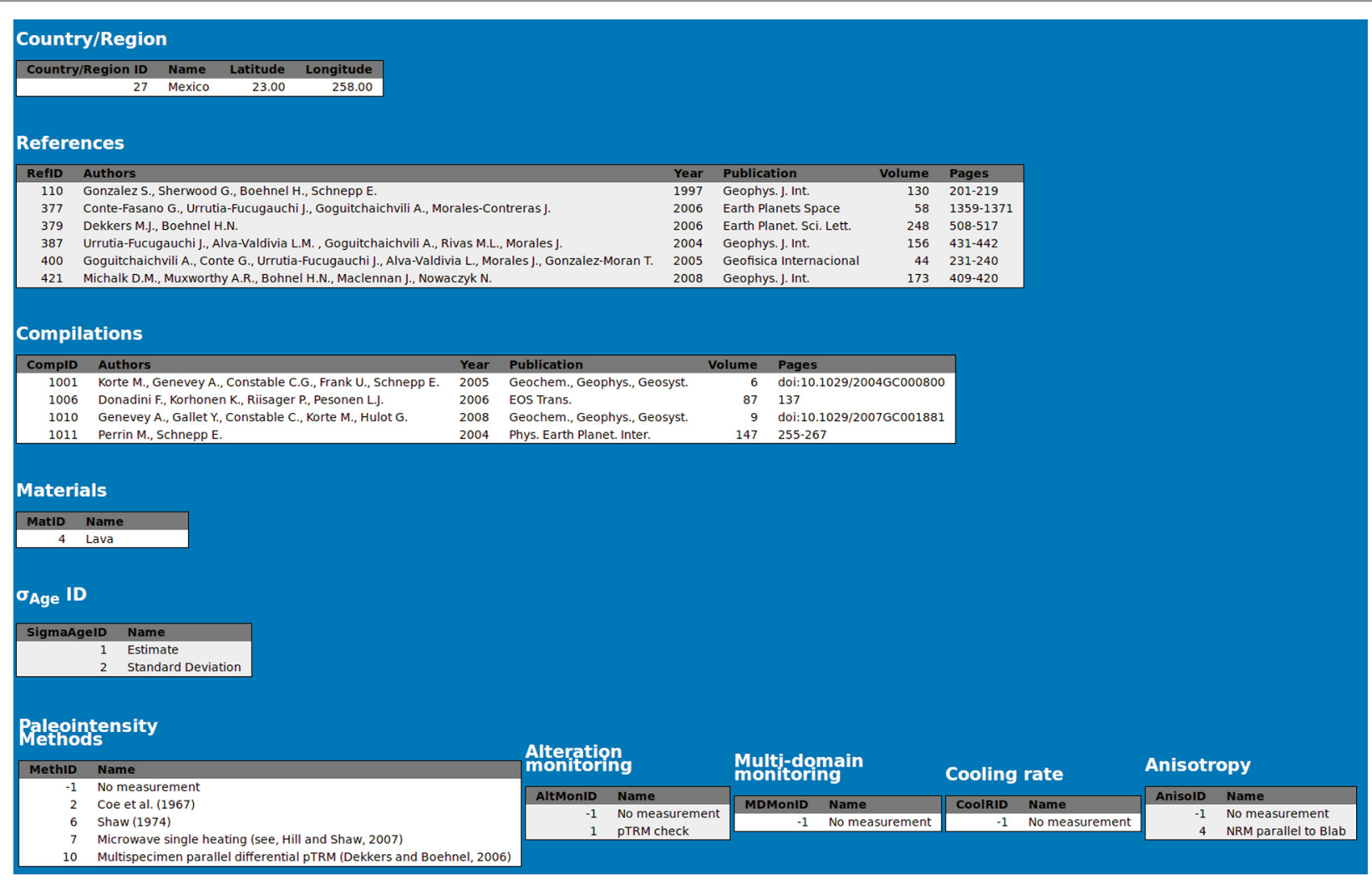

Figure 8 Example HTML metadata tables generated below the 'Query results' table on the 'Magnetic data' tab (Fig 7) for a detailed query. Geographic constraints: 'Location' = Michoacan - Guanajuato Volcanic Field - Paricutin.

of archeomagnetic and volcanic data, and a redesigned web page. The database will expand as more studies in archeomagnetism, paleomagnetism, and sediment magnetism are produced and we continue to add legacy data. The database is designed to be dynamic and respond to the needs of the community and we encourage the community to participate in the quality control of the database and report errors when they are found (contact information can be found on the home page of the web site).

The global distribution of archeological, volcanic, and sediment locations compiled for the database highlights both temporal and spatial deficiencies in data coverage over the past $50 \mathrm{ka}$, with archeomagnetic and volcanic data biased towards the past 2000 years and all data types dominated by locations in the Northern Hemisphere. We

\begin{tabular}{|c|c|c|c|c|c|c|c|c|c|}
\hline Magnetic data & \multicolumn{2}{|c|}{ Radiocarbon ages } & \multicolumn{3}{|c|}{ Figures \& Downloads } & \multicolumn{4}{|c|}{ Google Visualization } \\
\hline \multicolumn{10}{|c|}{ Radiocarbon Data } \\
\hline \multicolumn{10}{|c|}{ Found 4 matching entries. } \\
\hline C14 ID & ple Name & Dec. & Inc. & $\mathrm{Ba}$ & Pub. Age & Pub. $\sigma_{\text {Age }}$ & C14 Sample Code & Uncal C14 Age & Uncal sigma C14 Age \\
\hline & & $\left({ }^{\circ}\right)$ & $\left({ }^{\circ}\right)$ & $(\mu \mathrm{T})$ & (yr. AD) & (yr. AD) & & (yr. BP) & (yr. BP) \\
\hline 221 & VBT1 & 2.2 & 60.5 & 64.20 & 601 & 55 & UE323/LTL3438A & 1382 & 35 \\
\hline 221 & VBT1 & 2.2 & 60.5 & 64.20 & 601 & 55 & UE323/INV167 & 1449 & 27 \\
\hline 222 & VBK1 & 354.7 & 53.6 & 62.40 & 316 & 67 & UE23-UE1/INV1690BIS & 1729 & 27 \\
\hline 222 & VBK1 & 354.7 & 53.6 & 62.40 & 316 & 67 & UE40.23/LTL3439A & 1726 & 35 \\
\hline
\end{tabular}

Figure 9 An example of a 'Radiocarbon data' results table on the 'Radiocarbon ages' tab. Geographic constraints: 'Location' = Vega Baja (Catanzariti et al. 2012) 


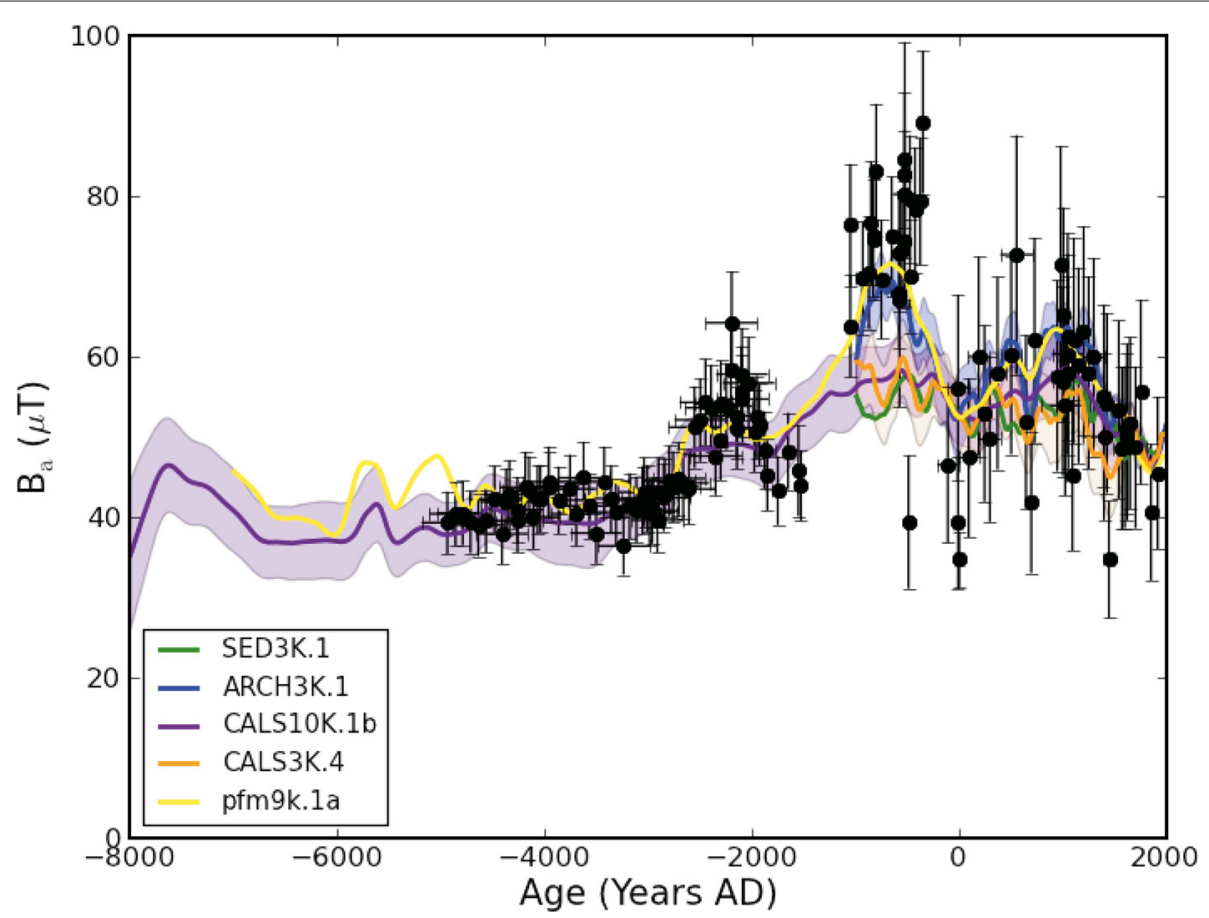

Figure 10 An example plot generated using Python and available on the 'Figures and Downloads' tab comparing paleointensity (Ba) data (black circles) and their associated uncertainties, with a series of model predictions and their associated uncertainties (colored lines with transparent envelopes) over the past 10 ka from Turkmenistan. Data from Burlatskaya et al. (1995), Nachasova and Burakov (1997), and Nachasova and Burakov (2000).

encourage researchers to investigate locations from the Southern Hemisphere and equatorial regions and to find new avenues in recovering archeomagnetic and volcanic data from times sparse in data.

\section{Availability and requirements \\ Project name: GEOMAGIA50}

Project home page: $\mathrm{http}: / /$ geomagia.gfz-potsdam.de/ Operating system(s): Platform and browser independent Programming language: PHP, SQL, HTML, JavaScript, Python, Fortran

Other requirements: Google Earth plug-in

License: none

Any restrictions to use by non-academics: none

\section{Additional file}

Additional file 1: User's Guide to GEOMAGIA50.v3: 1.

archeomagnetic and volcanic database. An additional file contains a user's guide to the archeological and volcanic database.

\section{Competing interests}

The authors declare that they have no competing interests.

\section{Authors' contributions}

MCB participated in implementing the web design and functionality of the archeomagnetic and volcanic database and drafted the manuscript. FD and KK developed the design of the database and implemented its underlying operational principles. FD acquired the data sources, populated the database, and participated in drafting of the manuscript. CGC, MK, and AN participated in aspects of the database design and contributed to the drafting of the manuscript. AL developed the Google Earth visualization coding and cross checked data entries. SNL acquired a number of North American data sources. All authors read and approved the final manuscript.

\section{Acknowledgements}

GEOMAGIA50 was initiated at the 5th Nordic Paleomagnetic Workshop, 25-30th September 2004, Suitia, Finland. It is an international collaboration funded by the US National Science Foundation (EAR-IF-0744107 and EAR-IF1225363) and Deutsche Forschungsgemeinshcaft (DFG) SPP PlanetMag 1488 (KO2870/4-1 and BR4697/1) (MK and MCB). FD acknowledges the support of the Swiss National Science Foundation (project numbers 130147 and 144102). AN was funded by the Natural Environment Research Council (NERC) grant NE/1013873/1 and the Swedish Research Council (Dnr 2014-4125). AL was funded by NERC grant NE/D002362/1. CGC gratefully acknowledges support from the Alexander von Humboldt Foundation and US National Science Foundation Grant NSF EAR 12225364. The authors would like to thank Mary Kovacheva (Bulgarian Academy of Sciences) for her assistance with the Bulgarian data sets. MCB thanks Martin Rother for his assistance with PHP and HTML coding and Alex Jordan for technical support. Some of the figures were produced using GMT (Wessel and Smith 1998). The contributions of all researchers who provided data and aided with comments on the structure and functionality of the database are greatly appreciated. We are grateful to Greig Paterson and an anonymous reviewer for their thoughtful comments.

\section{Author details}

'GFZ German Research Centre for Geosciences, Telegrafenberg, 14473 Potsdam, Germany. ${ }^{2}$ Department of Earth Sciences, University of Fribourg, Chemin du Musée 6, 1700 Fribourg, Switzerland. ${ }^{3}$ Geomagnetism Laboratory, Department of Earth, Ocean and Ecological Sciences, University of Liverpool, L69 7ZE Liverpool, UK. ${ }^{4}$ Current address: Department of Geology, Quaternary Sciences, Lund University, Sölvegatan 12, 223-62 Lund, Sweden. ${ }^{5}$ Geological Survey of Finland, P.O. Box 96 (Betonimiehenkuja 4), FI-02151 Espoo, Finland. ${ }^{6}$ Current address: AWE Blacknest, Brimpton, Reading, RG7 4RS, UK. ${ }^{7}$ llinois State Museum, Research and Collections Center, 1011 E. Ash Street, 
Springfield, Illinois, USA. ${ }^{8}$ Institute of Geophysics and Planetary Physics, Scripps Institution of Oceanography, University of California, San Diego, La Jolla, CA 92092-0225, USA.

\section{Received: 4 February 2015 Accepted: 17 April 2015 Published online: 12 May 2015}

\section{References}

Aitken MJ (1999) Archaeological dating using physical phenomena. Rep Prog Phys 62:1333-1376

Aitken MJ, Allsop AL, Bussell GD, Winter MB (1988) Determination of the intensity of the Earth's magnetic field during archaeological times: reliability of the Thellier technique. Reviews of Geophysics 26(1):3-12 doi:10.1029/RG026i001 p00003

Amit H, Korte M, Aubert J, Constable C, Hulot G (2011) The time-dependence of intense archeomagnetic flux patches. J Geophys Res 116:B12106. doi:10.1029/2011JB008538

Antoniades D, Francus P, Pienitz R, St-Onge G, Vincent WF (2011) Holocene dynamics of the Arctic's largest ice shelf. Proc Nat Acad Sci 108:18899-18904. doi:10.1073/pnas.1106378108

Arrighi S, Rosi M, Tanguy JC, Courtillot V (2004) Recent eruptive history of Stromboli (Aeolian Islands, Italy) determined from high-accuracy archeomagnetic dating. Geophys Res Lett 31:L19603. doi:10.1029/2004GL020627

Balco G, Stone JO, Lifton NA, Dunai TJ (2008) A complete and easily accessible means of calculating surface exposure ages or erosion rates from ${ }^{10} \mathrm{Be}$ and ${ }^{26} \mathrm{Al}$ measurements. Quaternary Geochronol 3:174-195. doi:10.1016/j.quageo.2007.12.001

Barletta F, St-Onge G, Channell JET, Rochon A (2010) Dating of Holocene western Canadian Arctic sediments by matching paleomagnetic secular variation to a geomagnetic field model. Quaternary Sci Rev 29:2315-2324. doi:10.1016/j.quascirev.2010.05.035

Biggin AJ (2010) Are systematic differences between thermal and microwave Thellier-type palaeointensity estimates a consequence of multidomain bias in the thermal results? Phys Earth Planet Inter 180:16-40. doi:10.1016/j.pepi.2010.03.005

Biggin AJ, Paterson GA (2014) A new set of qualitative reliability criteria to aid inferences on palaeomagnetic dipole moment variations through geological time. Frontiers Earth Sci 2:24. doi:10.3389/feart.2014.00024

Biggin AJ, Böhnel HN, Zúñiga FR (2003) How many paleointensity determinations are required from a single lava flow to constitute a reliable average? Geophys Res Lett 30:1575. doi:10.1029/2003GL017146

Biggin AJ, Perrin M, Shaw J (2007) A comparison of a quasi-perpendicular method of palaeointensity determination with other thermal and microwave techniques. Earth Planet Sci Lett 257:564-581. doi:10.1016/j.epsl.2007.03.016

Biggin AJ, Badejo S, Hodgson E, Muxworthy AR, Shaw J, Dekkers MJ (2013) The effect of cooling rate on the intensity of thermoremanent magnetization (TRM) acquired by assemblages of pseudo-single domain, multidomain and interacting single-domain grains. Geophys J Int 193(3):1239-1249. doi:10.1093/gji/ggt078

Bowles J, Gee JS, Kent DV, Bergmanis E, Sinton J (2005) Cooling rate effects on paleointensity estimates in submarine basaltic glass and implications for dating young flows. Geochem Geophys Geosyst 6:Q07002. doi:10.1029/2004GC000900

Bowles J, Gee JS, Kent DV, Perfit MR, Soule SA, Fornari DJ (2006) Paleointensity applications to timing and extent of eruptive activity, $9^{\circ}-10^{\circ} \mathrm{N}$ East Pacific Rise. Geochem Geophys Geosyst 7:Q06006. doi:10.1029/2005GC001141

Bowles JA, Jackson MJ, Berquó TS, Solheid PA, Gee JS (2013) Inferred time- and temperature-dependent cation ordering in natural titanomagnetites. Nat Commun 4:1916. doi:10.1038/ncomms2938

Boyd M (1986) A new method for measuring palaeomagnetic intensities. Nature 319:208-209. doi:10.1038/319208a0

Böhnel H, Michalk D, Nowaczyk N, Naranjo GG (2009) The use of mini-samples in palaeomagnetism. Geophys J Int 179(1):35-42. doi:10.1111/j.1365-246X.2009.04260.x

Bronk Ramsey C, Staff RA, Bryant CL, Brock F, Kitagawa H, van der Plicht J, Schlolaut G, Marshall MH, Brauer A, Lamb HF, Payne RL, Tarasov PE, Haraguchi T, Gotanda K, Yonenobu H, Yokoyama Y, Tada R, Nakagawa T (2012) A complete terrestrial radiocarbon record for 11.2 to $52.8 \mathrm{kyr}$ B.P Science 338:370-374. doi:10.1126/science.1226660
Brown MC, Holme R, Bargary A (2007) Exploring the influence of the non-dipole field on magnetic records for reversals and excursions. Geophys J Int 168:541-550. doi:10.1111/j.1365-246X.2006.03234.x

Brown MC, Donadini F, Frank U, Panovska S, Nilsson A, Korhonen K, Schuberth M, Korte M, Constable CG (2015) GEOMAGIA50,v3: 2. a new paleomagnetic database for lake and marine sediments. Earth Planets Space 67:70. doi:10.1186/s40623-015-0233-z

Burakov KS, Nachasova IE (1985) Correcting for chemical change during heating in archeomagnetic determinations of the ancient geomagnetic field intensity. Izvestiya Phys Solid Earth 21:801-803

Burakov KS, Nachasova IE (2013) Archaeomagnetic study and rehydroxylation dating of fired-clay ceramics. Izvestiya Phys Solid Earth 49:105-112

Burlatskaya SP, Lykov AV, Chernykh IE (1995) Geomagnetic field variations in Central Asia for the last 4000 years. Phys Solid Earth 31:407-416

Castro J, Brown L (1987) Shallow paleomagnetic directions from historic lava flows, Hawaii. Geophys Res Lett 14(12):1203-1206. doi:10.1029/GL014i012p01203

Catanzariti G, Gómez-Paccard M. McIntosh G, Pavón-Carrasco FJ, Chauvin A, Osete ML (2012) New archaeomagnetic data recovered from the study of Roman and Visigothic remains from central Spain (3rd-7th centuries). Geophys J Int 188(3):979-993. doi:10.1111/j.1365-246X.2011.05315.x

Channell JET, Xuan C, Hodell DA (2009) Stacking paleointensity and oxygen isotope data for the last 1.5 Myr (PISO-1500). Earth Planet Sci Lett 283:14-23. doi:10.1016/j.epsl.2009.03.012

Chauvin A, Garcia Y, Lanos Ph, Laubenheimer F (2000) Paleointensity of the geomagnetic field recovered on archaeomagnetic sites from France. Phys Earth Planet Inter 120(1-2):111-136. doi:10.1016/50031-9201(00)00148-5

Christensen UR, Aubert J, Hulot G (2011) Conditions for Earth-like geodynamo models. Earth Planet Sci Lett 296:487-496. doi:10.1016/j.epsl.2010.06.009

Clark RM (1975) A calibration curve for radiocarbon dates. Antiquity 49:251-266

Clark RM (1979) Calibration, cross-validation and carbon-14. I. J R Stat Soc A 142:47-62. doi:10.2307/2344653

Codd EF (1970) A relational model of data for large shared data banks. Communciations of the ACM 13:377-387. doi:10.1145/362384.362685

Coe RS (1967a) The determination of paleo-intensities of the Earth's magnetic field with an emphasis on mechanisms which could cause non-ideal behaviour in Thellier's method. J Geomag Geoelectr 19:157-179. doi:10.5636/jgg.19.157

Coe RS (1967b) Paleo-intensities of the Earth's magnetic field determined from Tertiary and Quaternary rocks. J Geophys Res 72(12):3247-3262. doi:10.1029/JZ072i012p03247

Coe RS, Grommé S, Mankinen EA (1978) Geomagnetic paleointensities from radiocarbon-dated lava flows on Hawaii and the question of the Pacific nondiple low. J Geophys Res 83(B4):1740-1756. doi:10.1029/JB083iB04p01740

Constable C, Korte M (2015) Centennial- to millennial-scale geomagnetic field variations. In: Treatise on Geophysics, Second Edition. Elsevier, Amsterdam, Netherlands

Constable CG, Johnson CL, Lund SP (2000) Global geomagnetic field models for the past 3000 years: transient or permanent flux lobes?. Phil Trans R Soc Lond A 358:991-1008. doi:10.1098/rsta.2000.0570

Constable C, Koppers A, Tauxe L, Minnett RC (2006) Five dimensions of MaglC. EOS Trans AGU 87(52):13-1172

Cottrell RD, Tarduno JA (1999) Geomagnetic paleointensity derived from single plagioclase crystals. Earth Planet Sci Lett 169:1-5. doi:10.1016/S0012-821X(99)00068-0

Davies CJ, Constable CG (2014) Insights from geodynamo simulations into long-term geomagnetic field behaviour. Earth Planet Sci Lett 404:238-249. doi:10.1016/j.epsl.2014.07.042

Delaygue G, Bard E (2011) An Antarctic view of Beryllium-10 and solar activity for the past millennium. Climate Dyn 36:2201-2218. doi:10.1007/s00382-010-0795-

Dekkers MJ, Böhnel HN (2006) Reliable absolute palaeointensities independent of magnetic domain state. Earth Planet Sci Lett 248:508-517. doi:10.1016/j.epsl.2006.05.040

De Marco E, Spatharas V, Gómez-Paccard M, Chauvin A, Kondopoulou D (2008) New archaeointensity results from archaeological sites and variation of the geomagnetic field intensity for the last 7 millennia in Greece. Phys Chem Earth, Parts A/B/C 33(6-7):578-595. doi:10.1016/j.pce.2008.02.025

de Vries $\mathrm{H}$ (1958) Variation in concentration of radiocarbon with time and location on earth. Koninkl Nederl Akad Wetenschappen Proc B61:94-102 
Di Chiara A, Speranza F, Porreca M, Pimentel A, D'Ajello Caracciolo F, Pacheco J (2014) Constraining chronology and time-space evolution of Holocene volcanic activity on the Capelo Peninsula (Faial Island, Azores): The paleomagnetic contribution. Geol Soc Am Bull 126:1164-1180. doi:10.1130/B30933.1

Domen H (1977) A single heating method of paleomagnetic field intensity determination applied to old roof tiles and rocks. Phys Earth Planet Inter 13(4):315-318. doi:10.1016/0031-9201(77)90115-7

Donadini F, Korhonen K, Riisager P, Pesonen LJ (2006) Database for Holocene geomagnetic intensity information. EOS Trans AGU 87(14):137-143. doi:10.1029/2006EO140002

Donadini F, Riisager P, Korhonen K, Kahmae K, Pesonen L, Snowball I (2007) Holocene geomagnetic paleointensities: A blind test of absolute paleointensity techniques and materials. Phys Earth Planet Inter 161:19-35. doi:10.1016/j.pepi.2006.12.002

Donadini F, Korte M, Constable CG (2009) Geomagnetic field for 0-3 ka: 1. New data sets for global modeling. Geochem Geophys Geosyst 10:Q06007. doi:10.1029/2008GC002295

Donadini F, Korte M, Constable C (2010) Millennial variations of the geomagnetic field: from data recovery to field reconstruction. Space Sci Rev 155:219-246. doi:10.1007/s11214-010-9662-y

Dumberry M, Bloxham J (2006) Azimuthal flows in the Earth's core and changes in length of day at millennial timescales. Geophys J Int 165:32-46. doi:10.1111/j.1365-246X.2006.02903.x

Dumberry M, Finlay CC (2007) Eastward and westward drift of the Earth's magnetic field for the last three millennia. Earth Planet Sci Lett 254:146-157. doi:10.1016/j.epsl.2006.11.026

Dunlop DJ (2011) Physical basis of the Thellier-Thellier and related paleointensity methods. Phys Earth Planet Inter 187:118-138. doi:10.1016/j.pepi.2011.03.006

Eighmy JL, Sternberg RS (1990) Archaeomagnetic Dating. University of Arizona Press, USA

Evans ME (1986) Paleointensity estimates from Italian kilns. J Geomag Geoelectr 38:1259-1267. doi:10.5636/jgg.38.1259

Fabian K, Leonhardt R (2009) Records of paleomagnetic field variations. In: Geomagnetic Field Variations. Advances in Geophysical and Environmental Mechanics and Mathematics. Springer, Berlin Heidelberg. pp 65-106. doi:10.1007/978-3-540-76939-2_3

Fabian K, Leonhardt R (2010) Multiple-specimen absolute paleointensity determination: An optimal protocol including pTRM normalization, domain-state correction, and alteration test. Earth Planet Sci Lett 297:84-94. doi:10.1016/j.epsl.2010.06.006

Fanjat G, Camps P, Alva Valdivia LM, Sougrati MT, Cuevas-Garcia M, Perrin M (2013) First archeointensity determinations on Maya incense burners from Palenque temples, Mexico: New data to constrain the Mesoamerica secular variation curve. Earth Planet Sci Lett 363:168-180. doi:10.1016/j.epsl.2012.12.035

Ferk A, v. Aulock FW, Leonhardt R, Hess K-U, Dingwell DB (2010) A cooling rate bias in paleointensity determination from volcanic glass: An experimental demonstration. J Geophys Res 115:B08102. doi:10.1029/2009JB006964

Ferk A, Leonhardt R, Hess K-U, Koch S, Egli R, Krása D, Dingwell DB (2014) Influence of cooling rate on thermoremanence of magnetite grains: Identifying the role of different magnetic domain states. J Geophys Res 119(3):1599-1606. doi:10.1002/2013JB010845

Fisher RA (1953) Dispersion on a sphere. Proc R Soc Lond A 217:295-305. doi:10.1098/rspa.1953.0064

Fournier A, Hulot G, Jault D, Kuang W, Tangborn A, Gillet N, Canet E, Aubert J, Lhuillier F (2010) An introduction to data assimilation and predictability in geomagnetism. Space Sci Rev 155:247-291. doi:10.1007/s11214-010-9669-4

Fox JMW, Aitken MJ (1980) Cooling-rate dependency of thermoremanent magnetisation. Nature 283:462-463. doi:10.1038/283462a0

Gallet Y, Hulot G, Chulliat A, Genevey A (2009) Geomagnetic field hemispheric asymmetry and archeomagnetic jerks. Earth Planet Sci Lett 284:179-186. doi:10.1016/j.epsl.2009.04.028

Genevey A, Gallet Y (2002) Intensity of the geomagnetic field in western Europe over the past 2000 years: New data from ancient French pottery. J Geophys Res 107(B11):2285. doi:10.1029/2001JB000701

Genevey A, Gallet Y, Boudon G (2002) Secular variation study from non-welded pyroclastic deposits from Montagne Pelée volcano, Martinique (West
Indies). Earth Planet Sci Lett 201(2):369-382.

doi:10.1016/S0012-821X(02)00713-6

Genevey A, Gallet Y, Constable CG, Korte M, Hulot G (2008) Archeolnt: An upgraded compilation of geomagnetic field intensity data for the past ten millennia and its application to the recovery of the past dipole moment. Geochem Geophys Geosyst 9:Q04038. doi:10.1029/2007GC001881

Goguitchaichvili A, Loponte D, Morales J, Acosta A (2010) The archaeointensity of the Earth's magnetic field retrieved from Pampean ceramics (South America). Archaeometry 54:388-400. doi:10.1111/j.1475-4754.2011.00620.x

Goguitchaichvili A, Greco C, Morales J (2011) Geomagnetic field intensity behavior in South America between 400 AD and 1800 AD: First archeointensity results from Argentina. Phys Earth Planet Inter 186:191-197. doi:10.1016/j.pepi.2011.03.007

Gonzalez S, Sherwood G, Böhnel H, Schnepp E (1997) Palaeosecular variation in Central Mexico over the last 30000 years: the record from lavas. Geophys J Int 130(1):201-219. doi:10.1111/j.1365-246X.1997.tb00999.x

Gómez-Paccard M, Chauvin A, Lanos P, Mclntosh G, Osete ML, Catanzariti G, Ruiz-Martínez VC, Núñez JI (2006a) First archaeomagnetic secular variation curve for the Iberian Peninsula: Comparison with other data from western Europe and with global geomagnetic field models. Geochem Geophys Geosyst 7:Q12001. doi:10.1029/2006GC001476

Gómez-Paccard M, Catanzariti G, Ruiz-Martínez VC, McIntosh G, Núñez Jl, Osete ML, Chauvin A, Lanos Ph, Tarling DH, Bernal-Casasola D, Thiriot J, Archaeological WorkingGroup (2006b) A catalogue of Spanish archaeomagnetic data. Geophys J Int 166(3):1125-1143. doi:10.1111/j.1365-246X.2006.03020.x

Hagstrum JT, Blinman E (2010) Archeomagnetic dating in western North America: An updated reference curve based on paleomagnetic and archeomagnetic data sets. Geochem Geophys Geosyst 11:Q06009. doi:10.1029/2009GC002979

Halgedahl SL, Day R, Fuller M (1980) The effect of cooling rate on the intensity of weak-field TRM in single-domain magnetite. J Geophys Res 85(B7):3690-3698. doi:10.1029/JB085iB07p03690

Haltia-Hovi E, Nowaczyk N, Saarinen T (2011) Environmental influence on relative palaeointensity estimates from Holocene varved lake sediments in Finland. Phys Earth Planet Inter 185:20-28. doi:10.1016/j.pepi.2010.12.002

Hammo Yassi NB (1987) Archaeomagnetic work in Iraq. Sumer 45:70-80

Hartmann GA, Genevey A, Gallet Y, Trindade RIF, Etchevarne C, Le Goff M, Afonso M (2010) Archeointensity in Northeast Brazil over the past five centuries. Earth Planet Sci Lett 296:340-352. doi:10.1016/j.epsl.2010.05.016

Hartmann GA, Genevey A, Gallet Y, Trindade RIF, Le Goff M, Najjar R, Etchevarne C, Afonso MC (2011) New historical archeointensity data from Brazil: Evidence for a large regional non-dipole field contribution over the past few centuries. Earth Planet Sci Lett 306:66-76 doi:10.1016/j.epsl.2011.03.030

Heimpel MH, Evans ME (2013) Testing the geomagnetic dipole and reversing dynamo models over Earth's cooling history. Phys Earth Planet Inter 224:124-131. doi:10.1016/j.pepi.2013.07.007

Hellio G, Gillet N, Bouligand C, Jault D (2014) Stochastic modelling of regional archaeomagnetic series. Geophys J Int 199(2):931-943. doi:10.1093/gji/ggu303

Hill MJ, Shaw J (1999) Palaeointensity results for historic lavas from Mt Etna using microwave demagnetization/remagnetization in a modified Thellier-type experiment. Geophys J Int 139:583-590. doi:10.1046/j.1365-246x.1999.00980.x

Hill MJ, Shaw J (2007) The use of the 'Kono perpendicular applied field method' in microwave palaeointensity experiments. Earth Planets Space 59:711-716. doi:10.1186/BF03352734

Holcomb R, Champion D, McWilliams M (1986) Dating recent Hawaiian lava flows using paleomagnetic secular variation. Geol Soc Am Bull 97(7):829-839. doi:10.1130/0016-7606(1986)97<829:DRHLFU>2.0.CO;2

Irving E (1959) Palaeomagnetic pole positions: a survey and analysis. Geophys J R astr Soc 2:51-79. doi:10.1111/j.1365-246X.1959.tb05781.X

Jarboe NA, Koppers AA, Tauxe L, Minnett R, Constable C (2012) The online MagIC Database: data archiving, compilation, and visualization for the geomagnetic, paleomagnetic and rock magnetic communities. Am Geophys Union Fall Meet Abstr 1:1063

Jonkers ART (2007) Discrete scale invariance connects geodynamo timescales Geophys J Int 171:581-593. doi:10.1111/j.1365-246X.2007.03551.x

Kapper KL, Donadini F, Mauvilly M, Panovska S, Hirt AM (2014) New directional archeomagnetic data of burned cave sediments from Switzerland and 
geomagnetic field variations in Central Europe. Geophys J Int 198:1208-1221. doi:10.1093/gji/ggu184

Kellogg K, Larson EE, Watson DE (1970) Thermochemical remanent magnetization and thermal remanent magnetization: Comparison in a basalt. Science 170:628-630. doi:10.1126/science.170.3958.628

Kirschvink JL (1980) The least-squares line and plane and the analysis of palaeomagnetic data. Geophys J R astr Soc 62:699-718. doi:10.1111/j.1365-246X.1980.tb02601.x

Knudsen MF, Riisager P (2009) Is there a link between Earth's magnetic field and low-latitude precipitation? Geology 37:71-74. doi:10.1130/G25238A.1

Knudsen MF, Riisager P, Donadini F, Snowball I, Muscheler R, Korhonen K, Pesonen LJ (2008) Variations in the geomagnetic dipole moment during the Holocene and the past 50 kyr. Earth Planet Sci Lett 272:319-329. doi:10.1016/j.epsl.2008.04.048

Kono M (1978) Reliability of palaeointensity methods using alternating field demagnetization and anhysteretic remanence. Geophys J R astr Soc 54:241-261. doi:10.1111/j.1365-246X.1978.tb04258.x

Kono M, Ueno N (1977) Paleointensity determination by a modified thellier method. Phys Earth Planet Inter 13:305-314. doi:10.1016/0031-9201(77)90114-5

Korhonen K, Donadini F, Riisager P, Pesonen L (2008) GEOMAGIA50: An archeointensity database with PHP and MySQL. Geochem Geophys Geosyst 9:Q04029. doi:10.1029/2007GC001893

Korte M, Constable C (2003) Continuous global geomagnetic field models for the past 3000 years. Phys Earth Planet Inter 140:73-89. doi:10.1016/j.pepi.2003.07.013

Korte M, Constable CG (2005) Continuous geomagnetic field models for the past 7 millenia: 2. CALS7K. Geochem Geophys Geosyst 6:Q02H16. doi:10.1029/2004GC000801

Korte M, Constable CG (2006) On the use of calibrated relative paleointensity records to improve millennial-scale geomagnetic field models. Geochem Geophys Geosyst 7:Q09004. doi:10.1029/2006GC001368

Korte M, Constable C (2011) Improving geomagnetic field reconstructions for 0-3 ka. Phys Earth Planet Inter 188:247-259. doi:10.1016/j.pepi.2011.06.017

Korte M, Holme R (2010) On the persistence of geomagnetic flux lobes in global field models. Phys. Earth Planet. Int. 182:179-186. doi:10.1016/j.pepi.2010.08.006

Korte M, Stolze S (2014) Variations in Mid-Latitude auroral activity during the Holocene. Archaeometry. doi:10.1111/arcm.12152

Korte M, Genevey A, Constable CG, Frank U, Schnepp E (2005) Continuous geomagnetic field models for the past 7 millenia: 1. A new global data compilation. Geochem Geophys Geosyst 6:Q02H15. doi:10.1029/2004GC000800

Korte M, Donadini F, Constable CG (2009) Geomagnetic field for 0-3 ka: 2. A new series of time-varying global models. Geochem Geophys Geosyst 10:Q06008. doi:10.1029/2008GC002297

Korte M, Constable C, Donadini F, Holme R (2011) Reconstructing the Holocene geomagnetic field. Earth Planet Sci Lett 312:497-505. doi:10.1016/j.epsl.2011.10.031

Kosterov AA, Prévot M (1998) Possible mechanisms causing failure of Thellier palaeointensity experiments in some basalts. Geophys J Int 134:554-572. doi:10.1046/j.1365-246x.1998.00581.x

Kovaltsov GA, Mishev A, Usoskin IG (2012) A new model of cosmogenic production of radiocarbon ${ }^{14} \mathrm{C}$ in the atmosphere. Earth Planet Sci Lett 337-338:114-120. doi:10.1016/j.epsl.2012.05.036

Kovacheva M, Boyadziev Y, Kostadinova-Avramova M, Jordanova N, Donadini F (2009) Updated archeomagnetic data set of the past 8 millennia from the Sofia laboratory, Bulgaria. Geochem Geophys Geosyst 10:Q05002. doi:10.1029/2008GC002347

Kovacheva M, Kostadinova-Avramova M, Jordanova N, Lanos Ph, Boyadzhiev Y (2014) Extended and revised archaeomagnetic database and secular variation curves from Bulgaria for the last eight millennia. Phys Earth Planet Inter 236:79-94. doi:10.1016/j.pepi.2014.07.002

Kuang W, Tangborn A, Jiang W, Liu D, Sun Z, Bloxham J, Wei Z (2008) MoSST_DAS: the first generation geomagnetic data assimilation framework. Comm Comp Phys 3:85-108

Kuang W, Tangborn A, Wei Z, Sabaka T (2009) Constraining a numerical geodynamo model with 100 years of surface observations. Geophys J Int 179:1458-1468. doi:10.1111/j.1365-246X.2009.04376.x

Lanza R, Meloni A, Tema E (2005) Historical measurements of the Earth's magnetic field compared with remanence directions from lava flows in
Italy over the last four centuries. Phys Earth Planet Inter 148:97-107. doi:10.1016/j.pepi.2004.08.005

Ledu D, Rochon A, de Vernal A, St-Onge G (2010) Holocene paleoceanography of the northwest passage, Canadian Arctic Archipelago. Quaternary Sci Rev 29:3468-3488. doi:10.1016/j.quascirev.2010.06.018

Le Goff M, Gallet Y (2004) A new three-axis vibrating sample magnetometer for continuous high-temperature magnetization measurements: applications to paleo- and archeo-intensity determinations. Earth Planet Sci Lett 229:31-43. doi:10.1016/j.epsl.2004.10.025

Le Goff M, Gallet Y (2014) Evaluation of the rehydroxylation dating method: Insights from a new measurement device. Quaternary Geochronol 20:89-98. doi:10.1016/j.quageo.2013.12.001

Leonhardt R, Heunemann C, Krása D (2004a) Analyzing absolute paleointensity determinations: acceptance criteria and the software ThellierTool4.0. Geochem Geophys Geosyst 5:Q12016. doi:10.1029/2004GC000807

Leonhardt R, Krása D, Coe RS (2004b) Multidomain behavior during Thellier paleointensity experiments: a phenomenological model. Phys Earth Planet Inter 147:127-140. doi:10.1016/j.pepi.2004.01.009

Leonhardt R, Matzka J, Nichols ARL, Dingwell DB (2006) Cooling rate correction of paleointensity determination for volcanic glasses by relaxation geospeedometry. Earth Planet Sci Lett 243:282-292. doi:10.1016/j.epsl.2005.12.038

Levi S (1977) The effect of magnetite particle size on paleointensity determinations of the geomagnetic field. Phys Earth Planet Inter 13:245-259. doi:10.1016/0031-9201(77)90107-8

Licht A, Hulot G, Gallet Y, Thébault E (2013) Ensembles of low degree archeomagnetic field models for the past three millennia. Phys Earth Planet Inter 224:38-67. doi:10.1016/j.pepi.2013.08.007

Lifton N, Smart DF, Shea MA (2008) Scaling time-integrated in situ cosmogneic nuclide production rates using a continuous geomagnetic model. Earth Planet Sci Lett 268:190-201. doi:10.1016/j.epsl.2008.01.021

Lifton N, Sato T, Dunai TJ (2014) Scaling in situ cosmogenic nuclide production rates using analytical approximations to atmospheric cosmic-ray fluxes. Earth Planet Sci Lett 386:149-160. doi:10.1016/j.epsl.2013.10.052

Linford P (1995) Archaeomagnetic Dating Report, Morton Fen, Bourne, Lincolnshire. Ancient Monuments Laboratory Report 4/95:1-9

Liritzis L, Lagios E (1993) A global archeomagnetic intensity data bank. Eos Trans AGU 74(27):303-306. doi:10.1029/93EO00276

Livermore PW, Fournier A, Gallet Y (2014) Core-flow constraints on extreme archeomagnetic intensity changes. Earth Planet Sci Lett 387:145-156. doi:10.1016/j.epsl.2013.11.020

Lodge A, Korte M (2009) Improving the visualization and interpretation of inhomogeneous data sets. Eos Trans AGU 90(19):167-168. doi:10.1029/2009EO190002

Lock J, McElhinny MW (1991) The global paleomagnetic database: design, installation and use with ORACLE. Surv Geophys 12:317-491. doi:10.1007/BF01996925

Lodge A, Holme R (2009) Towards a new approach to archaeomagnetic dating in Europe using geomagnetic field modelling. Archaeometry 51:309-322. doi:10.1111/j.1475-4754.2008.00400.x

Mandea M, Korte M, Mozzoni D, Kotzé P (2007) The magnetic field changing over the southern African continent: a unique behaviour. S Afr J Geol 110:193-202. doi:10.2113/gssajg.110.2-3.193

Márton P (2010) Two thousand years of geomagnetic field direction over central Europe revealed by indirect measurements. Geophys J Int 181:261-268. doi:10.1111/j.1365-246X.2010.04507.x

Márton P, Ferencz E (2006) Hierarchical versus stratification statistical analysis of archaeomagnetic directions: the secular variation curve for Hungary. Geophys J Int 164(3):484-489. doi:10.1111/j.1365-246X.2006.02873.X

McElhinny MW, Lock J (1996) IAGA paleomagnetic databases with Access. Surv Geophys 17:575-591. doi:10.1007/BF01888979

Mellström A, Nilsson A, Stanton T, Muscheler R, Snowball I, Suttie N (2015) Post-depositional remanent magnetization lock-in depth in precisely dated varved sediments assessed by archaeomagnetic field models. Earth Planet Sci Lett 410:186-196. doi:10.1016/j.epsl.2014.11.016

Michczyński A (2007) Is it possible to find a good point estimate of a calibrated radiocarbon date? Radiocarbon 49:393-401

Mitra R, Tauxe L, Mclntosh SK (2013) Two thousand years of archeointensity from West Africa. Earth Planet Sci Lett 364:123-133. doi:10.1016/j.epsl.2012.12.027

Muxworthy AR (2010) Revisiting a domain-state independent method of palaeointensity determination. Phys Earth Planet Inter 179:21-31. doi:10.1016/j.pepi.2010.01.003 
Muxworthy AR, Heslop D (2011) A Preisach method for estimating absolute paleofield intensity under the constraint of using only isothermal measurements: 1. Theoretical framework. J Geophys Res 116(B4):B04102. doi:10.1029/2010JB007843

Nachasova IE, Burakov KS (1997) Intensity of the geomagnetic field in Central Asia in 2000 BC - 1000 BC. Phys Solid Earth 33:543-548

Nachasova IE, Burakov KS (2000) The geomagnetic field intensity in Central Asia from 6000 to 3000 BC. Phys Solid Earth 36:358-363

Nagata T, Kobayashi K (1963) Thermo-chemical remanent magnetization of rocks. Nature 197:476-477. doi:10.1038/197476a0

Nagata T, Arai Y, Momose K (1963) Secular varaition of the geomagnetic force during the last 5000 years. J Geophys Res 68:5277-5281

Néel L (1949) Théorie du traînage magnétique des ferromagnétiques en grains fins avec applications aux terre cuites. Ann. Géophys 5:99-136

Neukirch LP, Tarduno JA, Huffman TN, Watkeys MK, Scribner CA, Cottrell RD (2012) An archeomagnetic analysis of burnt grain bin floors from ca. 1200 to 1250 AD Iron-Age South Africa. Phys Earth Planet Inter 190-191:71-79. doi:10.1016/j.pepi.2011.11.004

Nilsson A, Snowball I, Muscheler R, Uvo CB (2010) Holocene geocentric dipole tilt model constrained by sedimentary paleomagnetic data. Geochem Geophys Geosyst 11:Q08018. doi:10.1029/2010GC003118

Nilsson A, Holme R, Korte M, Suttie N, Hill M (2014) Reconstructing Holocene geomagnetic field variation: new methods, models and implications. Geophys J Int 198:229-248. doi:10.1093/gji/ggu120

Olson P, Deguen R (2012) Eccentricity of the geomagnetic dipole caused by lopsided inner core growth. Nat Geosci 5:565-569. doi:10.1038/ngeo1506

Ozima M, Ozima M, Akimoto S (1964) Low temperature characteristics of remanent magnetization of magnetite-self-reversal and recovery phenomena of remanent magnetization. J Geomag Geoelectr 16:165-177. doi:10.5636/jgg.16.165

Panovska S, Korte M, Finlay CC, Constable CG (2015) Limitations in paleomagnetic data and modelling techniques and their impact on Holocene geomagnetic field models. Geophys J Int 202:402-418. doi:10.1093/gii/ggv137

Paterson GA (2011) A simple test for the presence of multidomain behavior during paleointensity experiments. J Geophys Res 116:B10104. doi:10.1029/2011JB008369

Paterson GA, Heslop D, Muxworthy AR (2010) Deriving confidence in paleointensity estimates. Geochem Geophys Geosyst 11(7):Q07Z18. doi:10.1029/2010GC003071

Paterson GA, Biggin AJ, Yamamoto Y, Pan Y (2012) Towards the robust selection of Thellier-type paleointensity data: The influence of experimental noise. Geochem Geophys Geosyst 13:Q05Z43. doi:10.1029/2012GC004046

Paterson GA, Tauxe L, Biggin AJ, Shaar R, Jonestrask LC (2014) On improving the selection of Thellier-type paleointensity data. Geochem Geophys Geosyst 15:1180-1192. doi:10.1002/2013GC005135

Pavón-Carrasco FJ, Osete ML, Torta JM, Gaya-Piqué LR (2009) A regional archeomagnetic model for Europe for the last 3000 years, SCHA.DIF.3K: Applications to archeomagnetic dating. Geochem Geophys Geosyst 10:003013. doi:10.1029/2008GC002244

Pavón-Carrasco FJ, Osete ML, Torta JM (2010) Regional modeling of the geomagnetic field in Europe from 6000 to 1000 B.C. Geochem Geophys Geosyst 11:Q11008. doi:10.1029/2010GC003197

Pavón-Carrasco FJ, Osete ML, Torta JM, De Santis A (2014a) A geomagnetic field model for the Holocene based on archaeomagnetic and lava flow data. Earth Planet Sci Lett 388:98-109. doi:10.1016/j.epsl.2013.11.046

Pavón-Carrasco FJ, Gómez-Paccard M, Hervé G, Osete ML, Chauvin A (2014b) Intensity of the geomagnetic field in Europe for the last 3 ka: Influence of data quality on geomagnetic field modeling. Geochem Geophys Geosyst 15:2515-2530. doi:10.1002/2014GC005311

Pavón-Carrasco FJ, Tema E, Osete ML, Lanza R (2014c) Statistical analysis of palaeomagnetic data from the last four centuries: Evidence of systematic inclination shallowing in lava flow records. Pure Appl Geophys. doi:10.1007/s00024-014-0946-0

Perrin M, Schnepp E (2004) IAGA paleointensity database: distribution and quality of the data set. Phys Earth Planet Inter 147:255-267. doi:10.1016/j.pepi.2004.06.005

Perrin M (1998) Paleointensity determinations, magnetic domain structure, and selection criteria. J Geophys Res 103(B12):30591-30600. doi:10.1029/98JB01466

Piper JDA (1989) Palaeomagnetism, in Geomagnetism, Edited by J, A. Jacobs. vol. 3. Academic Press, London
Pisarevsky S (2005) New edition of the Global Paleomagnetic Database. EOS Trans AGU 86(17):170-170. doi:10.1029/2005EO170004

Prévot M, Mankinen EA, Coe RS, Grommé CS (1985) The Steens Mountain (Oregon) geomagnetic polarity transition 2. Field intensity variations and discussion of reversal models. J Geophys Res 90(B12):10417-10448. doi:10.1029/JB090iB12p10417

Reimer PJ, Baillie MGL, Bard E, Bayliss A, Beck JW, Blackwell PG, Bronk Ramsey C, Buck CE, Burr GS, Edwards RL, Friedrich M, Grootes PM, Guilderson TP Hajdas I, Heaton TJ, Hogg AG, Hughen KA, Kaiser KF, Kromer B, McCormac FG, Manning SW, Reimer RW, Richards DA, Southon JR, Talamo S, Turney CSM, van der Plicht J, Weyhenmeyer CE (2009) IntCal09 and Marine09 radiocarbon age calibration curves, $0-50,000$ years cal BP. Radiocarbon 51:1111-11150

Reimer PJ, Bard E, Bayliss A, Beck JW, Blackwell PG, Bronk Ramsey C, Buck CE,

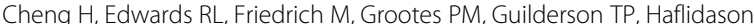
H, Hajdas I, Hatté C., Heaton TJ, Hoffmann DL, Hogg AG, Hughen KA, Kaiser KF, Kromer B, Manning SW, Niu M, Reimer RW, Richards DA, Scott EM, Southon JR, Staff RA, Turney CSM, van der Plicht J (2013) IntCal13 and Marine13 radiocarbon age calibration age curves $0-50,000$ years cal BP. Radiocarbon 55:1869-1887

Riisager P, Riisager J (2001) Detecting multidomain magnetic grains in Thellier palaeointensity experiments. Phys Earth Planet Inter 125:111-117. doi:10.1016/S0031-9201(01)00236-9

Roberts AP, Tauxe L, Heslop D (2013) Magnetic paleointensity stratigraphy and high-resolution Quaternary geochronology: successes and future challenges. Quat Sci Rev 61:1-16. doi:10.1016/j.quascirev.2012.10.036

Rogers J, Fox JMW, Aitken MJ (1979) Magnetic anisotropy in ancient pottery. Nature 277:644-646. doi:10.1038/277644a0

Rolph TC, Shaw J (1985) A new method of paleofield magnitude correction for thermally altered samples and its application to Lower Carboniferous lavas. Geophys J R astr Soc 80:773-781. doi:10.1111/j.1365-246X.1985.tb05124.x

Selesnick RS, Looper MD, Mewaldt RA (2007) A theoretical model of the inner proton radiation belt. Space Weather 5:S04003. doi:10.1029/2006SW000275

Schimmelpfennig I, Benedetti L, Garreta V, Pik R, Blard P-H, Burnard P, Bourlès D, Finkel R, Ammon K, Dunai T (2011) Calibration of cosmogenic ${ }^{36} \mathrm{Cl}$ production rates from $\mathrm{Ca}$ and $\mathrm{K}$ spallation in lava flows from Mt. Etna ( $38^{\circ} \mathrm{N}$, Italy) and Payun Matru ( $36^{\circ} \mathrm{S}$, Argentina). Geochimica et Cosmochimica Acta 75:2611-2632. doi:10.1016/j.gca.2011.02.013

Schnepp E, Lanos P (2006) A preliminary secular variation curve for archeomagnetic dating in Austria. Geophys J Int 166:91-96. doi:10.1111/j.1365-246X.2006.03012.x

Shaar R, Ben-Yosef E, Ron H, Tauxe L, Agnon A, Kessel R (2011) Geomagnetic field intensity: How high can it get? How fast can it change? Constraints from Iron Age copper slag. Earth Planet Sci Lett 301:297-306. doi:10.1016/j.epsl.2010.11.013

Shaw J (1974) A new method of determining the magnitude of the palaeomagnetic field. Application to five historic lavas and five archaeological samples. Geophys J R astr Soc 39:133-141. doi:10.1111/j.1365-246X.1974.tb05443.x

Shaw J, Walton D, Yang S, Rolph TC, Share JA (1996) Microwave archaeointensities from Peruvian ceramics. Geophys J Int 124:241-244 doi:10.1111/j.1365-246X.1996.tb06367.x

Snowball I, Muscheler R (2007) Palaeomagnetic intensity data: an Achilles heel of solar activity reconstructions. The Holocene 17:851-859. doi:10.1177/0959683607080531

Smith PJ (1967) Ancient geomagnetic field intensities-I Historic and archaeological data: Sets H1-H9. Geophys J R astr Soc 13:417-419. doi:10.1111/j.1365-246X.1967.tb03140.x

Speranza F, Pompilio M, D’Ajello Caracciolo F, Sagnotti L (2008) Holocene eruptive history of the Stromboli volcano: Constraints from paleomagnetic dating. J Geophys Res 113:B09101. doi:10.1029/2007JB005139

Stark F, Cassidy J, Hill MJ, Shaw J, Sheppard P (2010) Establishing a first archaeointensity record for the SW Pacific. Earth Planet Sci Lett 298:113-124. doi:10.1016/j.epsl.2010.07.031

Sternberg RS, Deaver WL, Kuter EA, Kiley AL (1997) A North American archaeomagnetic database. J Geomag Geoelectr 49:519-522. doi:10.5636/jgg.49.519

Stuiver M, Polach HA (1977) Reporting of ${ }^{14} \mathrm{C}$ data. Radiocarbon 19:355-363

Suess HE (1970) Bristlecone Pine Calibration of the Radiocarbon Time Scale from 5400 BC to the Present. Radiocarbon Variations and Absolute Chronology. Wiley, New York 
Suttie N, Shaw J, Hill MJ (2010) Direct demonstration of microwave demagnetization of a whole rock sample with minimal heating. Earth Planet Sci Lett 292:357-362. doi:10.1016/j.epsl.2010.02.002

Suttie N, Holme R, Hill MJ, Shaw J (2011) Consistent treatment of errors in archaeointensity implies rapid decay of the dipole prior to 1840. Earth Planet Sci Lett 304:13-21. doi:10.1016/j.epsl.2011.02.010

Tanaka H, Komuro N (2009) The Shaw paleointensity method: Can the ARM simulate the TRM alteration? Phys Earth Planet Inter 173:269-278. doi:10.1016/j.pepi.2009.01.003

Tanaka H, Hashimoto Y, Morita N (2012) Palaeointensity determinations from historical and Holocene basalt lavas in Iceland. Geophys J Int 189:833-845. doi:10.1111/j.1365-246X.2012.05412.x

Tanguy JC (1975) Intensity of the geomagnetic field from recent Italian lavas using a new paleointensity method. Earth Planet Sci Lett 27:314-320. doi:10.1016/0012-821X(75)90043-6

Tarling DH, Dobson MJ (1995) Archaeomagnetism: An error assessment of fired material observations in the British directional database. J Geomag Geoelectr 47:5-18. doi10.5636/jgg.47.5

Tauxe L, Yamazaki T (2007) 5.13 - paleointensities. In: Schubert G (ed). Treatise on Geophysics. Elsevier, Amsterdam. pp 509-563. doi:10.1016/B978-044452748-6.00098-5. http://www.sciencedirect.com/ science/article/pii/B9780444527486000985

Taylor RE, Bar-Yosef O (2014) Radiocarbon Dating, Second Edition: An Archaeological Perspective. Left Coast Press, Walnut Creek, California, USA

Telford RJ, Heegaard H, Birks HJB (2004) The intercept method is a poor estimate of a calibrated radiocarbon age. The Holocene 14:296-298. doi:10.1191/0959683604hl707fa

Tema E, Kondopoulou D (2011) Secular variation of the Earth's magnetic field in the Balkan region during the last eight millennia based on archaeomagnetic data. Geophys J Int 186(2):603-614. doi:10.1111/j.1365-246X.2011.05088.x

Tema E, Hedley I, Lanos P (2006) Archaeomagnetism in Italy: a compilation of data including new results and a preliminary Italian reference curve. Geophys J Int 167:1160-1171. doi:10.1111/j.1365-246X.2006.03150.x

Thellier E (1941) Sur les propriétés de l'aimantation thermorémanente des terres cuites. C. R. Acad. Sci. Paris 213:1019-1022

Thellier $E$ (1977) Early research on the intensity of the ancient geomagnetic field. Phys Earth Planet Inter 13:241-244. doi:10.1016/0031-9201(77)90106-6

Thellier E, Thellier O (1959) Sur l'intensité du champ magnétique terrestre dans le passé historique et géologique. Ann Géophys 15:285-376

Tsunakawa H, Shaw J (1994) The Shaw method of palaeointensity determinations and its application to recent volcanic rocks. Geophys J Int 118:781-787. doi:10.1111/j.1365-246X.1994.tb03999.x

Usoskin IG, Solanki SK, Korte M (2006) Solar activity reconstructed over the last 7000 years: The influence of geomagnetic field changes. Geophys Res Lett 33:L08103. doi:10.1029/2006GL025921

Usoskin IG, Korte M, Kovaltsov GA (2008) Role of centennial geomagnetic changes in local atmospheric ionization. Geophys Res Lett 35:L05811. doi:10.1029/2007GL033040

Usoskin IG, Mironova IA, Korte M, Kovaltsov GA (2010) Regional millennial trend in the cosmic ray induced ionization of the troposphere. J Atmos Sol Terr Phys 72:19-25. doi:10.1016/j.jastp.2009.10.003

Valet J-P (2003) Time variations in geomagnetic intensity. Rev Geophys 41:1004. doi:10.1029/2001RG000104

Valet J-P, Herrero-Bervera E (2000) Paleointensity experiments using alternating field demagnetization. Earth Planet Sci Lett 177:43-58. doi:10.1016/S0012-821X(00)00036-4

Valet J-P, Plenier G (2008) Simulations of a time-varying non-dipole field during geomagnetic reversals and excursions. Phys Earth Planet Inter 169:178-193. doi:10.1016/j.pepi.2008.07.031

Valet J-P, Brassart J, Le Meur I, Soler V, Quidelleur X, Tric E, Gillot P-Y (1996) Absolute paleointensity and magnetomineralogical changes. J Geophys Res 101(B11):25029-25044. doi:10.1029/96JB02115

Valet J-P, Tric E, Herrero-Bervera E, Meynadier L, Lockwood JP (1998) Absolute paleointensity from Hawaiian lavas younger than $35 \mathrm{ka}$. Earth Planet Sci Lett 161(1-4):19-32. doi:10.1016/S0012-821X(98)00133-2

Valet J-P, Meynadier L, Guyodo Y (2005) Geomagnetic dipole strength and reversal rate over the past two million years. Nature 435:802-805. doi:10.1038/nature03674
Valet J-P, Plenier G, Herrero-Bervera E (2008) Geomagnetic excursions reflect an aborted polarity state. Earth Planet Sci Lett 274:472-478. doi:10.1016/j.epsl.2008.07.056

Valet J-P, Fournier A, Courtillot V, Herrero-Bervera E (2012) Dynamical similarity of geomagnetic field reversals. Nature 490(doi:10.1038/nature11491):89-93 van der Plicht J (2004) Radiocarbon, the calibration curve and Scythian chronology. In: Scott EM, Alekseev AY, Zaitseva Gl, Division NATOSA (eds). Impact of the Environment on Human Migration in Eurasia: Proceedings of the NATO Advanced Research Workshop, Held in St. Petersburg, 15-18 November 2003. Kluwer Academic, Netherlands. pp 45-61

van Zijl JSV, Graham KWT, Hales AL (1962) The palaeomagnetism of the Stormberg Lavas of South Africa, II. The behaviour of the magnetic field during a reversal. Geophys J R astr Soc 7:169-182. doi:10.1111/j.1365-246X.1962.tb00366.x

Veikkolainen T, Pesonen LLJ, Evans DA (2014) PALEOMAGIA: A PHP/MYSQL database of the Precambrian paleomagnetic data. Studia Geophysica et Geodaetica 58(3):425-441. doi:10.1007/s11200-013-0382-0

Veitch RJ, Hedley IG, Wagner JJ (1984) An investigation of the intensity of the geomagnetic field during Roman times using magnetically anisotropic bricks and tiles. Arch. Sci. Genève 37:359-373

Venkatachalapathy R, Asanulla RM, Manoharan C, Radhakrishna T (2013) Rock magnetic and geomagnetic field intensity studies on Megalithic archaeological pottery samples from Tamilnadu, India. Quaternary Int 298:57-57. doi:10.1016/j.quaint.2013.02.028

Villasante-Marcos V, Pavón-Carrasco FJ (2014) Palaeomagnetic constraints on the age of Lomo Negro volcanic eruption (El Hierro, Canary Islands). Geophys J Int 199(3):1497-1514. doi:10.1093/gji/ggu346

Walker M (2005) Quaternary Dating Methods. Wiley, Chichester, West Sussex, England

Walton D (1977) Archaeomagnetic intensity measurements using a SQUID magnetometer. Archaeometry 19:192-200. doi:10.1111/j.1475-4754.1977.tb00198.x

Walton D (1990) The intensity of the geomagnetic field in the Eastern Mediterranean between 1600 BC and AD 400. J Geomag Geoelectr 42:929-936. doi:10.5636/jgg.42.929

Wardinski I, Korte M (2008) The evolution of the core-surface flow over the last seven thousands years. J Geophys Res 113:B05101. doi:10.1029/2007JB005024

Wessel P, Smith WHF (1998) New, improved version of Generic Mapping Tools released. EOS Trans AGU 79:579. doi:10.1029/98EO00426

Wilson RL (1961) Paleomagnetism in Northen Ireland, Part I, The thermal demagnetization of natural magnetic moments in rocks. Geophys J R astr Soc 5:45-58. doi:10.1111/j.1365-246X.1961.tb02928.x

Wilson MA, Carter MA, Hall C, Hoff WD, Ince C, Savage SD, Mckay B, Betts IM (2009) Dating fired-clay ceramics using long-term power law rehydroxylation kinetics. Proc R Soc Lond A 465:2407-2415 doi:10.1098/rspa.2009.0117

Yamamoto Y, Tsunakawa H, Shibuya H (2003) Palaeointensity study of the Hawaiian 1960 lava: implications for possible causes of erroneously high intensities. Geophys J Int 153:263-276. doi:10.1046/j.1365-246X.2003.01909.x

Yu Y, Dunlop DJ (2003) On partial thermoremanent magnetization tail checks in Thellier paleointensity determination. J Geophys Res 108:2523. doi:10.1029/2003JB002420

Yu Y, Dunlop DJ, Özdemir O (2003) Effect of low-temperature treatments on pseudo-Thellier paleointensity determination. J Geophys Res 108:2198. doi:10.1029/2002JB002138

Yu Y, Tauxe L, Genevey A (2004) Toward an optimal geomagnetic field intensity determination technique. Geochem Geophys Geosyst 5:Q02H07. doi:10.1029/2003GC000630

Zananiri I, Batt CM, Lanos Ph, Tarling DH, Linford P (2007) Archaeomagnetic secular variation in the UK during the past 4000 years and its application to archaeomagnetic dating. Phys Earth Planet Inter 160(2):97-107. doi:10.1016/j.pepi.2006.08.006

Ziegler LB, Constable CG, Johnson CL (2008) Testing the robustness and limitations of 0-1 Ma absolute paleointensity data. Phys Earth Planet Inter 170(1-2):34-45. doi:10.1016/j.pepi.2008.07.027 